Erst bei einer künftigen Gelegenheit möchte ich den Versuch machen, die Bedeutung der hier geschilderten Verhältnisse eingehender zu erörtern.

Zum Schluss sei es mir gestattet, Herrn Dr. E. Fränkel, Prosector am allgemeinen Krankenhause in Hamburg, dessen Gefälligkeit ich die beiläufig erwähnten untersuchten Menschenaugen verdanke, und welcher auch die Güte hatte, einzelne meiner Präparate einzusehen, meinen besten Dank auszusprechen.

\title{
XXI.
}

\section{Zur Morphologie der Blutbildung im Knochenmark der Såugethiere.}

Von Dr. Obrastzow aus Petersburg.

(Hierzu Taf. IX.)

Neumann ${ }^{1}$ und Bizzozero ${ }^{6}$ haben bekanntlich schon Ende der sechziger Jahre auf's Unzweifelhafteste nachgewiesen, dass das rothe Knochenmark der Säugethiere ein Blutbildungsorgan vorstellt, und dass die rothen kernhaltigen Zellen, welche man beim gesunden Thier bier mehr oder weniger reichlich antrifft, "Uebergangsformen" von den farblosen Markzellen zu den rothen Blutkörperchen darstellen; die Art und Weise dieses Ueberganges war von diesen Gelehrten jedoch keineswegs festgestellt. Die unmittelbare Histogenese dieser Elemente einerseits, andererseits der Modus, wie sie ihren Kern verlieren und dadurch kernlose Bildungen, rothe Blutkörperchen, entstehen, waren so wenig aufgeklärt, dass Neumann selbst, auf Grund seiner Untersuchungen über die Blutbildung an Embryonen von Säugethieren im Jahre 1874 an dem Zusammenhang der Uebergangsformen mit den Leucocyten zweifelt ( $\left.{ }^{2} \mathrm{~S} .466\right)$ und vorschlägt, die Bezeichnung "Uebergangsformen" fallen zu lassen und statt dessen die Bezeichnung „embryonale rothe Zellen", oder einfach „Entwickelungsformen " 3 zu gebrauchen. In gleicher Weise hält $\mathrm{R}$ indfleisch in seiner, im August 1879 erschienenen 
Arbeit ${ }^{7}$, den Zusammenhang der kernhaltigen rothen Zellen mit den Markzellen als nicht erwiesen. In dieser Hinsicht finden also die von Neumann erhobenen Zweifel auch von Seiten Rindfleisch's Unterstützung, hinsichtlich der Art und Weise aber, wie der Kern aus den kernhaltigen rothen Zellen verschwindet, geben die Ansichten beider Gelehrten auseinander. Rindfleisch konnte ein allmäbliches Kleinerwerden des Kernes bis zum vollständigen Schwund desselben nicht beobachten, fand dagegen, dass der Kern, welcher in der gefärbten Zelle gewöhnlich excentrisch liegt, sich der Peripherie nähert, und schliesslich allmählich aus der Zelle heraustritt. Der emigrirte Kern hinterlässt das gefärbte kernlose Protoplasma in Mïtzen- oder Glockenform, welche letztere während der Gefässcirculation, nach Rindfleisch, in biconcave Scheiben sich verwandelt.

Von, der ursprünglichen Kölliker'schen ${ }^{9}$ Lehre über die Morphologie der Blutbildung bei Säugethieren, welche in der ersten Arbeit Neumann's vollständige Bestätigung gefunden batte, blieb somit nur das eine übrig, dass die ursprüngliche histologische Form des rothen Blutkörperchens die gefärbte kernhaltige Zelle ist.

Will man an dem Zusammenhang dieser Bildungen mit den Leucocyten zweifeln und leugnet man mit $R$ indfleisch ein allmähliches Kleinerwerden des Kernes, so bleiben mehrere, schon längst bekannte Thatsachen unerklärt. So hat ausser Kölliker auch Neumann ${ }^{2}$ dieses Kleinerwerden in den embryonalen rothen Zellen beobachtet; zu zweifeln an diesen übereinstimmenden Angaben ist man also nicht berechtigt, und dennoch sind diese, wenn auch nicht oft anzutreffenden Thatsachen von dem Standpunkte Rindfleisch's aus nicht zu erklären. In gleicher Weise unerklärt bleibt die Körnigkeit der rothen Blutkörperchen, welche von $\mathbf{E} \mathbf{r b}^{18}$ bei gewissen Zuständen des Organismus, welche eine vermehrte Blutbildung fordern, beobachtet ist, wenn der Kern in toto aus der gefärbten Zelle emigriren soll.

Das weitere Schicksal des emigrinten Kernes ist ferner im Stande, Bedenken zu erregen. Dasselbe wird geradezu räthselhaft, wenn man nicht annehmen will, dass aus demselben nachher ein Leucocyt sich bildet, dass somit die kernhaltigen rothen Zellen zu gleicher Zeit Hämato- und Leucoblasten sind. Dabei wird man jedoch an den Versuch Rindfleisch's ${ }^{8}$ erinnert, aus den rothen 
Blutkörperchen des Frosches farblose Blutkörperchen zu erzeugen, einen Versuch, der bekanntlich ohne Erfolg blieb ${ }^{32}$.

Nacbstehende Arbeit will nun den histogenetischen Zusammenhang aller Elemente des Knochenmarks und den der kernhaltigen rothen Zellen mit den farblosen Markzellen und rothen Blutkörperchen insbesondere genauer feststellen; dabei soll ein kurzer Blick auf die Ansichten geworfen werden, welche die Vorstadien der Bildung rother Blutkörperchen nicht in den kernhaltigen rothen Zellen des Knochenmarkes, sondern in verschiedenen, im Blute selbst circulirenden Elementen suchen.

Meine Untersuchungsmethoden waren von denen anderer Autoren, welche das Knochenmark untersucbten, in nichts unterschieden: ein Tropfen Marksaft wurde mit einer Knocbenzange aus einer Rippe herausgedrückt, oder es wurde ein Stückchen Knochenmark direct aus einers Röhrenknochen genommen und nach vorhergegangener Zerzupfung des Präparates oder ohne dieses in sogenannten indifferenten Flüssigkeiten untersucht; oder die Untersuchung geschah, wie es Neumann so angelegentlich empfiehlt, ohne Zusatz jeglichen Reagens im Markplasma selbst.

Von den indifferenten oder vielmehr den als solche geltenden Flüssigkeiten, als Kochsalzlösung, Jodserum, Humor aqueus, Serum, 0smiumsäure u. s. w., musste ich der Kochsalzlösung den Vorzug geben. Beim vollkommen frischen Knochenmark siud jedoch schwache Lösungen anzuwenden; eine $3 / 4$ procentige Lösung, wie sie von Rindfleis $c h$ gebraucht wurde, ist nur bei dem aus der Leiche genommenen Mark verwendbar, beim frischen Mark dagegen schrumpfen durch dieselbe alle Elemente desselben zu sehr zusammen. Ich bediente mich gewöhnlich einer 0,5 oder 0,6 procentigen Lösung, und gebrauchte erstere bei frischem, letztere bei der Leiche entnommenem Mark. Jodserum, Humor aqueus und das von Ranvier ( ${ }^{12} \mathrm{~S}$. 366) empfohlene gewöhnliche Serum eignen sich nur zur Untersuchung des der Leiche entnommenen Markes, im frischen Mark kommt durch dieselben Schrumpfen sämmtlicher Markelemente zu Stande. Durch Osmiumsäure (1 procentige Lösung) werden die Farbennüancen der Markelemente zu sehr verwischt. Als Maassstab für die Anwendbarkeit eines Reagens diente mir beim frischen Mark sein Verhalten zum Lichtbrechungsvermögen der Elemente: in einem geeigneten 
Reagens mussten die rothen Blutkörperchen, die Mark- und Uebergangszellen in gewissem Grade ein mattes Aussehen haben und die gefärbten Elemente ihre Hämoglobinfärbung bewahren.

Die Untersuchung des Knochenmarkes ohne Zusatz von Reagentien im Plasma selbst, wie es von Neumann so warm empfohlen, ist jedenfalls für Jeden, der sich mit Untersuchungen des Knochenmarkes abgiebt, unentbehrlich, jedoch nicht diese Methode allein, sondern in Verbindung mit der vorhergehenden. Untersucht man ohne Reagentien, so kann man freilich versichert sein, dass die erhaltenen Bilder durch keine fremden Substanzen bedingt sind; doch möge man nicht glauben, dass man bei einer derartigen Untersuchungsmethode die Markelemente unter ihren vitalen Verhältnissen beobachtet. Abgesehen davon, dass die Reaction des Plasma verändert wird, sobald das Mark aus dem lebenden Organismus entfernt wird, sind wir nicht im Stande, den zur Untersuchung bestimmten Tropfen vor Verdunstung zu schützen, was, wie wir weiter sehen werden, auf die von uns erhaltenen Bilder nicht ohne Einfluss bleiben kann. Im Weiteren wird es sich ergeben, warum die bei der einen Untersuchungsmethode erhaltenen Resultate durch die bei anderen Methoden erhaltenen controlirt werden müssen. Diese Controle der einen Methode durch die andere ist jedoch nur nothwendig und nützlich in dem Falle, wenn das zu untersuchende Mark dem lebenden oder soeben getödteten Thiere entnommen und sofort untersucht wird. Untersucht man dagegen das Knochenmark 24 Stunden nach dem Tode des Thieres, so findet man keinen ausgesprochenen und instructiven Unterschied, gleichgültig ob die Untersuchung nach Zusatz von Kochsalzlösung vorgenommen wird oder ohne jegliches Reagens. Bisher hat man auf die Zeit, wann das Knochenmark untersucht werde, zu wenig Gewicht gelegt; man bielt es nicht für durchaus nothwendig, dasselbe im vollkommen oder möglichst frischen Zustande zu untersuchen, und die Beschreibungen der verschiedenen Autoren entsprechen mehr oder weniger dem Leichenzustande der Markelemente.

Die Beobachtungen wurden angestellt mit Syst. 8, Ocul. 3, Immers. Syst. 10, 0cul. 3 und Immers. Syst. 12, 0cul. 3 Hartnack. 
Nimmt man aus der Knochenhöhle eines lebenden jungen Hundes das Mark und untersucht es sofort in einer 0,5 procentigen Kochsalzlösung, so enthält das Bild folgende Elemente:

1) Gewöhnliche rothe Blutkörperchen. Regelmässigen biconcaven Scheiben begegnet man hier nicht, meist haben sie eine wenig eckige Form, die sich bisweilen der kugligen nähert. Ihr Ausseben ist leicht matt, die Hämoglobinfärbung ist nicht scharf ausgesprochen. Ihre Grösse schwankt, so weit man darüber bei ihrer unregelmässigen Form urtheilen kann, annäbernd innerhalb derselben Grenzen, wie im Blute. Untersucht man dieselben Elemente ungefähr 2 Stunden nach Herstellung des verklebten Präparats, so bemerkt man, dass viele eckige Blutkörperehen die Kugelform angenommen baben, während die Hämoglobinfärbung bei allen schärfer bervortritt und sie weniger matt aussehen.

2. Ebenfalls gefärbte Zellen, dem Aussehen nach jedoch etwas dunkler, als die gewöhnlichen Blutkörperchen. Sie sind gleich letzteren homogen, matt, zeigen auch nicht die Spur eines Kernes, sind gewöhnlich von kugliger Form. Die Grösse dieser Zellen ist eine durchaus verschiedene, von 6-12 $\mu$. Es fallen meist nur voluminösere Repräsentanten dieser Gruppe auf; diejenigen, welche sich ihrer Grösse nach den rothen Blutkörperchen nähern, verlieren sich unter letzteren, da der Farbenunterschied zwischen beiden kein sehr scharf ausgesprochener ist und sich Uebergänge von den dunkleren zu denjenigen mit einem oormalen, relativ blassen Aussehen finden. Einige Zellen dieser Gruppe besitzen eine 8 förmige Gestalt, d. h. befinden sich im Theilungsprozess. Eine Schilderung der weiteren Veränderungen in diesen gefärbten, homogenen Zellen folgt weiter unten bei der Beschreibung identischer Veränderungen in den blassen Zellen.

Als Uebergang zur folgenden Gruppe trifft man gefärbte Zellen an, in welchen man bei aufmerksamem Zusehen neben dem peripherischen Contour einen zweiten bemerkt, nur leicht angedeutet und von dem peripherischen Contour durch einen kaum bemerkbaren, aus einer helleren Substanz bestehenden Rand getrennt. Fügt man zum Präparat in vorsichtiger Weise verdünnte (1 procentige) Essigsäure hinzu, so sieht man, dass der zweite Contour dem Kern angehört, welcher rasch zur Grösse eines kleinen glänzenden Kügelchens zusammenschrumpft. 
3. Kernhaltige rothe $\mathrm{Z}$ ellen von verschiedener Grösse, gleich der vorhergehenden Gruppe, von kugliger Form. Der Kern ist im Verhältniss zur Zelle gewöhnlich gross und nimmt einen grossen Theil derselben ein. Einen Theil seiner Peripherie hat er gemein mit der Peripherie der Zelle, wodurch der Kern gewöhnlich excentrisch erscheint. Das Aussehen des letzteren ist matt und homogen, ohne eine Spur etwa von Linien oder Pünktchen; Kernkörperchen finden sich ebenfalls nicht. Seine Gestalt ist eine kugelförmige, die Ränder sind regelmässig und glatt, der Contour nicht scharf ausgesprochen. Wenn der Kern einen grossen Theil der Zelle einnimmt und ein mattes Aussehen hat, so scheint es, als ob er gefärbt wäre; ist er aber im Verhältniss zur Grösse der Zelle klein, so erscheint er glänzend, und dann kann an seiner Farblosigkeit nicht gezweifelt werden. Hat das Präparat einige Zeit, etwa 2 Stunden gestanden, so gehen sowohl hinsichtlich der Gestalt der Zellen als auch des Aussehens des Kernes wesentliche Veränderungen vor sich. Statt der Kugelform nehmen die Zellen eine unregelmässige zackige Gestalt an, ähnlich wie man es bei den rothen Blutkörperchen beobachtet, nur dass ihre Ecken weniger regelmässig sind als bei letzteren. Nach einiger Zeit verändern sie gewöhnlich auch diese Gestalt und erscheinen nicht selten in Dreiecksform (im optischen Durchschnitt), in deren Mitte oder an einem der Winkel der Kern gelagert ist, oder sie nehmen die Spindelform an; nicht selten beobachtet man ferner nicht eine ganze, sondern nur eine halbe Spindel in Form eines ganzen oder abgestumpften Kegels. Bisweilen erscheinen sie ferner in Mützenform, an deren concaver Fläche der Kern liegt. Endlich nehmen einige die Form von Rhomben an; der Kern der letzteren befindet sich in einem der spitzen Winkel. Beobachtet man diese letzte Art von Zellen einige Zeit hindurch, so entdeckt man nicht selten, dass das Protoplasma an jenem Winkel, wo der Kern sich befindet, mit dem gesammten Zellenprotoplasma zu verschwimmen beginnt, wodurch die Zelle ein mehr rundes Aussehen erhält, der Winkel, in welchem der Kern liegt, allmählich stumpf wird und endlich verschwindet, wodurch der Kern zum Theil, ja sogar zur Hälfte ausserhalb der Zelle zu liegen kommt. - Auch der Kern geht gewisse Veränderungen ein. Seine Hornogenität und sein mattes Aussehen verschwinden allmählich; es tritt ein mehr oder weniger 
körniges Aussehen und eine Reihe geschlängelter Linien auf. Nicht selten verläuft die Strichelung neben den Körnern; in anderen Fällen bilden sich Balken, die unter einander in den verschiedensten Richtungen verflochten sind. Das Bild des Kernes wird dadurch gewöhnlich ein unregelmässiges, wenngleich man bisweilen einen Kern antrifft, in dem die Strichelung vom Centrum zu seiner Peripherie strahlenförmig verläuft; doch auch jetzt kann man kein Kernkörperchen entdecken. Statt des ursprünglichen matten Aussehens wird der Kern mehr und mehr glänzend, ja in einigen Zellen stärker geschrumpft, verliert er wiederum seine Zeichnung, d. h. die Strichelung und die Pünktchen, wird homogen, und sieht diamantähnlich glänzend aus.

Man begegnet ferner in dieser Gruppe Zellen von 8förmiger Gestalt, wobei jede Hälfte der sich auf diese Weise theilenden Zellen ihren besonderen Kern einschliesst. Letzterer entspricht sowohl seinem Aussehen nach, als auch binsichtlich der Veränderungen, die er eingeht, vollkommen dem Kern der soeben beschriebenen Form. Hinsichtlich des ursprünglichen Aussehens des Kernes in den Zellen dieser Gruppe ist es von Interesse, derartige 8 förmige Zellen anzutreffen, wo in den beiden Hälften der sich theilenden Zelle selbst kein Kern zu erblicken ist; dagegen sieht man hier an der Uebergangsstelle beider Hälften zwei ausserordentlich dünne bogenförmige Contouren, die mit ibren convexen Seiten neben einander liegen und unmittelbar in die peripherischen Contouren beider Hälften der sich theilenden Zelle übergehen. Die weiteren Veränderungen der 8 förmigen Zellen besteben in einem Ausgleichen beider Hälften, wodurch die Uebergangsstelle allmählich verschwindet, so dass die 8-Form in die ovale, ja runde übergeht. In beiden Fällen enthält nun die Zelle zwei gleich grosse Kerne.

Fugt man zum vollkommen frischen Präparat eine etwas gegesättigte $(0,6$ procentige) Kochsalzlösung hinzu, und lässt man das Präparat unverklebt, so bemerkt man nicht selten, dass die hellen Contouren der Kerne bei dieser Zellenform gleichsam sich zu verwischen anfangen; das Aussehen des Kernes wird verschwommener, das Protoplasma aber mehr eckig und glänzend. Diese Veränderungen können so weit gehen, dass die grosse, mit einer kaum bemerkbaren Protoplasmasichel versehene Zelle sich schliesslich in einen unregelmässigen, eckigen, bisweilen sogar stacheligen glän- 
zenden Klumpen verwandelt, bei dem es schwer fällt, sich über die Intensität der Hämoglobinfärbung ein Urtheil zu bilden.

Wenn man auf das frische Präparat vorsichtig eine 1procentige Serumlösung von Ammonium chromicum (Arndt) einwirken lässt, so beobacbtet man, wie unter dem Einfluss des Reagens in vielen Zellen dieser Kategorie der Kern sich vergrössert, seine Contouren sich mehr and mehr den peripherischen Contouren der Zelle nähern und schliesslich nicht selten vollkommen zusammenfliessen. Dies geschieht, ohne dass die Zelle ihre Hämoglobinfärbung einbüsst. Dieselbe, nur weniger ausgesprochene Wirkung sehen wir nach Zusatz von 33procentiger wässeriger Harnstofflösung. Doch bei Weitem nicht alle Kerne werden durch Zusatz genannter Reagentien so aufgebläht, dass ihre Contouren mit denen der Zellen zusammenfliessen: ist der Kern schon glänzend geworden, so verliert er unter dem Einfluss des Reagens zwar einiges an seinem Lichtbrechungsvermögen und nimmt an Grösse zu, dies jedoch nicht in einem Grade, wie der voluminöse und leicht matte Kern. Auf Zusatz von destillirtem Wasser wird der Kern bald homogen und bläht sich auf, bei gleichzeitiger rascher Entfärbung des Protoplasma. Die Zellen dieser Kategorie sind, wie gesagt, von verschiedener Grösse, von $4-5-12 \mu$, ja bisweilen selbst grösser. Werden die Zellenkerne sofort nach Anfertigung des frischen Präparates gemessen, so schwankt ihre Grösse annähernd zwischen denselben Grenzen, wie die Grösse der Zellen, d. h. sie beträgt annähernd $3-4-11 \mu$. Wird die Messung jedoch einige Zeit später, etwa 4-5 Stunden nach dem Tode des Thieres vorgenommen, so sind die Grenzen, innerhalb deren die Grösse der Kerne schwankt, weit enger geworden. Die Grösse der Kerne steht jetzt auch nicht einmal annähernd mit der Grösse der Zellen im Einklang, und so findet man in den an Grösse total verschiedenen Zellen Kerne von gleicher Grösse, der Unterschied in der Grösse der Zellen dagegen wird durch den quantitativen Unterschied an Zellenplasma bedingt. So findet man letzteres in den allerkleinsten Zellen in Form einer schmalen, bisweilen kaum bemerkbaren, gefärbten Sichel, welche einen grösseren oder kleineren Theil umgiebt, in den grossen Zellen dagegen findet sich das Protoplasma in solcher Menge, dass der Kern sich gleichsam im Protoplasma oder Zellenkörper verliert. Die an Grösse gleichen Kerne haben auch eine gleiche Zeichnung, d. h. 
Körnelung und Streifung, Das kleinste Volumen besitzen die gleichmässig glänzenden, homogenen Kerne. Ihre Grösse beträgt annähernd $2-3 \mu$. Kleinere Kerne der gefärbten Zellen werden im Mark eines gesunden Thieres nicht beobachtet.

4. Blasse Markzellen mit homogenem Aussehen. Von Färbung ist in einigen von ihnen gar nichts zu entdecken, in anderen nur Spuren davon, doch so wenig deutlich ausgesprochen, dass man nicht selten nicht mit Bestimmtheit angeben kann, ob die betreffende Zelle die Hämoglobinfärbung aufweist oder nicht, ob sie also zu den "Uebergangsformen" zu rechnen ist oder nicht. In vielen dieser Zellen erblicken wir den Kern entweder gar nicht, oder, was häufiger der Fall ist, wir errathen ihn aus der Erweiterung des peripherischen Contours der Zelle, wobei der verstärkte Scbatten dieses Contours unmittelbar neben und nach innen von dem peripherischen gelegen ist. Man erhält den Eindruck, als ob zwei Contouren neben einander liegen und der innere schärfer nüancirt ist. Diese Erweiterung des Contours ist gewöhnlich nicht in der ganzen Peripherie in gleicher Weise ausgesprochen; oft sieht man sie an einem Pol vollkommen deutlich, wäbrend am anderen, namentlich dem gegenüber liegenden, nur ein linearer Contour zu erblicken ist. Wurde das Präparat rasch aus vollkommen frischem Mark angefertigt, so sieht man in diesen Zellen nicht selten folgende Veränderungen vor sich gehen: Zunächst Erweiterung des peripherischen Contours, darnach allmählich deutlicher werdende Abgrenzung zweier Contouren, die von einander durch eine ausserordentlich dünne, fast lineare Protoplasmasichel getrennt werden. Diese anfängliche Erweiterung setzt sich dann von dem einen Pol auch auf die benachbarte Peripherie fort, worauf ebenfalls die Scheidung des inneren Contours und Bildung eines schmalen Protoplasmareifs folgt. Am Ausgangspunkte hat sich inzwischen der innere Contour in so weit von dem äusseren entfernt, dass man ziemlich deutlich die Charaktere des Protoplasma, namentlich seine Färbung oder Farblosigkeit, feststellen kann; am gegenüberliegenden Pol dagegen, wo man anfangs nur den linearen Contour sehen konnte, sieht man jetzt eine dentliche Erweiterung, wenngleich oft noch ohne Trennung des inneren Contours. Im Allgemeinen kann man also sagen, dass der Kern zwar homogen bleibt, jedoch sich verk]einert und zusammen- 
schrumpft. Da die Trennung seines Contours vom peripherischen jedoch in der Regel nicht gleichzeitig an der ganzen Peripherie der Zelle zu Stande kommt, sondern vom einen Pol beginnend, allmählich fortschreitet, so wird sie am anderen, gewöhnlich dem entgegengesetzten Pol verzögert, und so sieht man schliesslich, dass der Kern za diesem Pol hin retrahirt wird, sein Centrum fällt also nicht mit dem der Zelle zusammen, der Kern nimmt eine excentrische Lage ein. Ist die Zelle nicht kuglig, sondern mehr oder weniger elliptisch, so findet der Trennungsprozess beider Contoure gewöhnlich zunächst an den vom Centrum entfernteren Polen statt, wobei dieser Prozess an beiden entgegengesetzten Polen zu gleicher Zeit zu Stande kommt.

Diese Reihe von Veränderungen in der Zelle zeigt sich am anschaulichsten beim vorsichtigen Zusatz von verdünnter Essigsäure zum Präparat. Hier sehen wir dann denselben oben beschriebenen Prozess, jedoch in rascherer Entwickelung: so sieht der Beobachter den Contourenspaltungsprozess rasch auf die ganze Peripherie sich erstrecken; der Kern, anfänglich an Umfang der Grösse der Zelle entsprechend, schrumpft nach einem Pol hin zusammen und liegt schliesslich excentrisch in Form einer glänzenden Linse oder eines Kügelchens.

Dieser Modus der Kernbildung wird, wie oben gesagt, bei Anwendung von Kochsalzlösung nur dann beobachtet, wenn das Präparat aus vollkommen frischem Knochenmark hergestellt wurde. Bewahrte jedoch eine Zelle von ungefähr $10-12 \mu$ Grösse nach Verlauf einer gewissen Zeit, 1-2 Stunden nach Herstellung der Präparats, ibr homogenes Aussehen, selbst ohne Erweiterung des peripherischen Contours, so bemerkt man bei fortdanernder Beobachtung an derselben eine Reihe von Erscheinungen ganz anderer Art, die man übrigens auch an den homogenen gefärbten Zellen der zweiten Gruppe oft noch deutlicher ausgesprochen beobachtet. Die homogene Zelle (im verklebten Präparat) wird zunächst trübe und hernach körnig. Die Körnigkeit ist zunächst nicht deutlich ausgesprochen, sie ist fein und verschwommen, doch nach kurzer Zeit werden die Körnchen grösser und glänzender; sie nehmen die ganze Zelle ein und sind in ihr gleichmässig verbreitet. Nach einiger Zeit bemerkt man, dass die einzelnen Körner in regelmässige Reihen sich ordnen, die in radiärer Richtung vom Centrum bis zur Peripherie verlaufen. 
Weiterhin treten die einzelnen Körner in Verbindung mit einander und statt der Reihen von Körnern entstehen Fasern, die ebenfalls regelmässig radiär vom Centrum der Zelle zur Peripherie verlaufen. Darauf bemerkt man ein Zusammenfliessen der Fasern zunächst im Centrum der Zelle, wo ein solider Körper sich bildet, von dem aus radiäre Strahlen zur Peripherie verlaufen. Diese letzteren fliessen ebenfalls zusammen und bilden dickere Strahlen, wobei mehrere Fäden von der Peripherie sich lostrennen, sich mit einander verbinden und zum Centrum sich zurückziehen, wodurch der hier befindliche solide Körper an Grösse zunimmt und die Form eines strahlenden Sternes bekommt. Die Strahlen haben die Gestalt eines Dreiecks, dessen Basis mit dem centralen Körper zusammenfliesst und dessen Spitze zur Peripherie der Zelle bin gelegen ist. Endlich lösen sich auch die Spitzen dieser Strahlen von der Peripherie ab und contrahiren sich zum Centrum hin; die Strahlen der centralen Körper werden kürzer und schliesslich verwandelt sich das Ganze in einen winkllgen, soliden, stark glänzenden Körper, welcher central gelegen ist. Dieser Körper ist selbstverständlich nichts anderes, als der Kern. Eine derartige Kernbildung werden wir im Ferneren als radiäre im Gegensatz zur ersteren, der concentrischen, bezeichnen.

Bisher war die Rede von Zellen, welche bis zum Anfang der Körnerbildnng keine Andeutungen eines Kernes bieten. Wählt man aber eine Zelle mit ausgesprochener Erweiterung des peripherischen Contours, oder mit bereits erfolgter Trennung beider Contoure und mit Bildung einer kaum bemerkbaren Protoplasmasichel, so sind die weiteren Veränderungen in einer solchen Zelle in gewissem Grade von den oben beschriebenen verschieden. Hier sieht man nach einiger Zeit die Deutlichkeit der Contourzeichnung des Kernes sich verlieren. Darauf bemerkt man, wie oben, eine Trübung und Körnigkeit, doch ist beides gewöhnlich nicht so regelmässig ausgesprochen, wie in den Zellen ohne Erweiterung des peripherischen Contours. Die Körner sind hier weit voluminöser und stellen sich nicht in Reihen, sondern fliessen unter einander zusammen und bilden mehr oder weniger dicke Balken, die sich unter einander verflechten. Diese Balken contrahiren sich darauf, doch nicht zur Mitte hin, sondern zu dem Pol der Zelle, in welchem vorher die Contourscheidung nicht $z u$ bemerken war. Hier präsentirt sich also, im Gegensatz zur radiären Kernbildung ein System von Balken, welche 
von dem Kerncontour eingeschlossen wird, während bei der radiären Kernbildung die Strahlen unmittelbar im Zellenprotoplasma liegen. Wir sehen also, dass sich hier der Kern zum Theil nach dem radiären, zum Theil nach dem concentrischen Modus bildete, diese Bildungsweise kann also als eine gemischte bezeichnet werden.

Bei der Kernbildung, namentlich nach dem concentrischen Modus, kann man mit Leichtigkeit Farbennüancen unterscheiden und man beobachtet daher, dass viele Zellen jetzt zur Gattung der ,kernhaltigen rothen Zellen" übergehen, wenn vielleicht auch die Intensität der Färbung weniger stark ausgesprocben ist.

Die Zellen dieser Kategorie sind ebenfalls von verschiedener Grösse. Doch besonders oft begegnet man dieser Form unter den kleineren farblosen Zellen, so dass man es als Regel hinstellen kann, dass je kleiner die farblose Zelle ist, um so öfter sie zu dieser Zellenkategorie gehört; die allerkleinsten Bildungen unter allen Elementen des Knochenmarkes gehören ausnahmslos zu den blassen Zellen. Die kleinsten blassen Zellen sind sofort nach Herstellung des Präparats matt, wobei oft bald an ihrer Oberfläche einige Körnchen auftreten und eine Membran sich bildet; letztere um so rascher und um so weiter von der Peripherie der Zelle entfernt, je schwächer die Kochsalzlösung. In concentrirten Lösungen wird diese Membran nicht beobachtet; man sieht dagegen, dass diese kleine Zelle ihr homogenes mattes Aussehen verliert, an ihrer Oberfläche eine Anzahl dunkler Streifen auftritt, welche ebenfalls verschwinden, und die Zelle sich in ein glänzendes homogenes Körperchen ohne eine Protoplasmasichel verwandelt; sie erscheint daher als blosser Kern, seiner Grösse und optischen Eigenthümlichkeiten nach nabestehend den Kernen, welche oben bei den kernhaltigen rothen Zellen nach ihrer schliesslichen Metamorphose beschrieben worden. In den Zellen dieser Kategorie, jedoch in den an Umfang etwas grösseren, als die so eben beschriebenen, kann man schon die Bildung der Protoplasmasichel beobachten, in der Regel, nachdem zunächst Erweiterung des peripherischen Contours vorausgegangen ist. Die Protoplasmasichel bleibt jedocb klein, selbst nachdem der Kern ein glänzendes und homogenes Aussehen angenommen hat; dabei ist sie so wenig deutlich, dass man hier oft schon nach erfolgter Kernbildung nicht bestimmen kann, ob das 
Protoplasma einer solchen Zelle gefärbt ist oder nicht. Die radiäre Kernbildung kommt hier nie zur Beobachtung.

Man begegnet blassen Zellen von 8-förmiger Gestalt. Die weiteren Veränderungen an diesen sind dieselben, wie sie oben für die 8-Form der vorhergehenden Gruppe geschildert wurden.

5. Gewöhnliche Markzellen. Diese bieten schon an Präparaten, welche aus ganz frischem Knochenmark hergestellt sind, ein versehiedenes Ausseben dar. Ihre Peripherie erscheint etwas dunkel und glänzend, das Centrum hell und matt. Es kommen jedoch Ausnahmen hiervon vor: nicht selten sieht man in der helleren Centralsubstanz einige dunklere Streifen, andererseits wird die dunklere Peripherie nicht selten von dicken Ausläufern durchbrochen, welche von der centralen blassen Substanz ihren Anfang nehmen. Die Grenze zwischen beiden Substanzen ist keine lineare, der Uebergang der einen in die andere ist vielmehr ein allmählicher, so dass man beim ersten Anblick keinen Kern sieht; erst nach einiger Uebung lernt man es, in der blassen Centralsubstanz die Kernmasse und in der peripherischen dunklen Substanz das Protoplasma zu errathen. Diese Differenzirung tritt in einigen Zellen ziemlich rasch auf. Man bemerkt, wie der dunkle Glanz der peripherischen Substanz an Intensität abnimmt und an Stelle der mehr oder weniger gleichmässigen dunklen Substanz eine Körnigkeit auftritt, wobei die Körner in einer wenig lichtbrechenden Substanz suspendirt sind. Sind diese Körnchen nicht voluminös und nicht zahlreich, so ist man bald darauf im Stande, zu beobachten, wie die Contouren des Kernes um die blasse centrale Substanz herum zum Vorschein kommen. Ist der Kern auf diese Weise nun sichtbar geworden, so beobachtet man in ihm einige Eigenthümlichkeiten, im Vergleich zu den Kernen der vorhergehenden Gruppen. Zunächst sieht man hier mehrere, gewöhnlich 3-4 Kernkörperchen, was bei Uebergangs- und blassen Zellen nicht der Fall war. Der Contour des Kernes ist hier scharf ausgesprochen, er erscheint verdickt und gleichsam doppelt, wodurch der Kern an ein Bläschen erinnert. Der Kern hat eine runde, ovale oder Nierenform. Letzteres Aussehen beobachtet man oft an den Zellen mit wenig ausgesprochen körnigem Protoplasma und mit punktförmigen Kernkörperchen im Kern. Eine solche Zelle kann anfangs leicht als eine blasse Zelle angesehen werden; man erwartet hier die Kernbildung in einer der oben 
beschriebenen Weisen, und erst bei weiterer Beobachtung überzeugt man sich von ihrer Zugehörigkeit zu den gewöhnlichen Markzellen. Die Contouren des Kernes in einer solchen Zelle liegen oft weite Strecken hin unmittelbar neben den Zellencontouren und eine Vertiefung an irgend einem Segment des Kernes und die immer deutlicher auftretenden Kernkörperchen weisen darauf hin, dass hier der Kern und seine Gestalt fertig gegeben sind. In anderen Zellen sieht man diese Vertiefung sich weiter erstrecken, sie ähnelt dadurch gleichsam einer Bucht, welche mit Protoplasma ausgefüllt ist, während der Kern Hufeisenform annimmt. In diesen Zellenformen ist eine Verdickung des Contours nicht zu erkennen. In den mehr körnigen Zellen trifft man diese Kernform selten an, statt dessen sieht man runde oder ovale Kerne mit Kernkörperchen und einem verdickten Contour. In der Regel findet sich in jeder Zelle nur ein Kern; 2 und 3 Kerne in einer Zelle werden selten angetroffen. Die 8-Form wird bei dieser Zellengattung nicht beobachtet. Die Grösse der Zellen ist verschieden, doch kann man im Gegensatz zu den blassen Zellen hier als Regel aufstellen, dass je grösser die farblose Markzelle ist, sie um so bäufiger dieser Gruppe angehört; die allergrössten farblosen Zellen gehören gewöhnlich hierher, und Ausnahmen hiervon kommen nur in pathologischen Fällen vor.

Werden diese Zellen längere Zeit hindurch beobachtet, und haben sie ihr körniges Aussehen angenommen, so sieht man ihr Ausseben sich nur wenig verändern. Verkleinerung des Kernes wird nur in den Zellen mit schwach ausgesprochener Körnigkeit des Protoplasma beobachtet: in diesen können ausser den Kernkörperchen etliche Striche und Pünktchen auftreten, doch bis zum glänzenden homogenen Zustande kommt es hier gewöhnlich nicht; in den Zellen mit stärker ausgesprochenen Körnern bleibt die Grösse der Kerne eine unveränderte.

Ausser diesen geschilderten besitzen die gewöbnlichen Markzellen noch zwei Eigenthümlichkeiten: das Vermögen, amöboide Bewegungen auszuführen, und das Bestreben, zusammenzufliessen. Die Făhigkeit, amöboide Bewegungen auszuführen, ist bei den gewöhnlichen Markzellen eine bedeutende; am deutlichsten manifestirt sie sich an den Zellen, welche ihrem Aussehen nach sich wenig von den hlassen Zellen mittlerer Grösse unterscheiden. Schon 10 his 
15 Minuten nach Anfertigung des Präparates sieht man an ihnen Auswüchse entstehen, und die Gestalt sich verändern. Diese Bewegungen gehen bei gewöhnlicher Zimmertemperatur ohne Heiztische vor sich. Zellen mit mehr ausgesprochen körnigem Protoplasma besitzen diese Bewegungsfähigkeit in weit geringerem Grade. Dagegen findet sich hier das Streben zusammenzufliessen und Haufen zu bilden, welche ihrem Aussehen nach rundlich oder oval erscheinen; bisweilen lagern sich die Zellen in Zügen, welche den Säulen mit queren Auswüchsen in Form von Aesten ähneln. Nach einiger Zeit verschwinden in solchen Haufen die Grenzen der Zellen, so dass man beim ersten Blick das ganze Bild als eine grosse körnige Zelle ansehen könnte, in welcher ovale Kerne zerstreut sind.

6. Myeloplaxen oder Riesenzellen des Knochenmarkes. Diese treten in zweierlei Art auf: 1) als Myeloplaxen mit körnigem Protoplasma, verschwommenen Contouren und im Protoplasma ziemlich regelmässig zerstreuten Kernen mit verdickten Contouren und mehreren (3-4) Kernkörperchen. Diese Kerne und Kernkörperchen sind oft sogleich nach Anfertigung des frischen Präparates nicht sichtbar und treten erst nach einiger Zeit auf. Ausser der runden und ovalen Form dieser Myeloplaxen beobachtet man die Säulenform mit mehr oder weniger dicken Aesten. 2) Myeloplaxen mit wenig körnigem und bisweilen fast hyalinem Protoplasma und einem sogenannten sprossenden Kern. - Ausser diesen zwei beschriebenen Formen beobachtet man oft Körnerhaufen ohne Kerne, welche letztere auch durch Essigsäure nicht sichtbar gemacht werden können, sowie Formen, in denen durch Essigsäure nicht nur die Contouren der Kerne, sondern auch die Grenzen der Zellen hervortreten. Als Uebergangsformen von den Myeloplaxen ersterer Art zu den Körnerhaufen kann man die letzteren Bildungen beobachten, in welchen durch Essigsäure noch einige einzelne Kerne auftreten; ihre Zahl (bisweilen nur 2-3) ist jedoch im Verbältniss zur Grösse der Zelle sehr minim.

7. Pigmentzellen und rothe Blutkörperchen enthaltende Zellen. Die einer wie die anderen finden sich im Knochenmark gesunder junger Thiere äusserst selten. Ferner begegnet man Bildungen von runder Form mit verdickten peripherischen Contouren und mehreren Kernkörperchen. Ihrer morphologischen und mikrochemischen Beschaffenheit nach müssen sie zu 
den wahren nackten Kernen gerechnet werden. Untersucht man kleine, nicht zerzupfte Stückchen vom Rnochenmark; so beobachtet man ferner Fettzellen, sowie Gefässe aller Art, darunter auch Capillaren, in welchen bisweilen nach der Richtung des Gefässes hin gestreckte rothe Blutkörperchen sichtbar sind. -

Nachdem wir auf diese Weise die Elemente des frischen Knochenmarks bei Untersuchung in einer schwachen Kochsalzlösung kennen gelernt haben, gehen wir über zur Schildernug des Bildes, welches dieselben Elemente darbieten, wenn sie ohne Zusatz von Reagentien im eigenen Markplasma untersucht werden. Zur Anfertigung eines solchen Präparates wurde hauptsächlich aus der Rippe ein Tropfen Marksaft ausgedrückt, dieser rasch mit einem Deckgläschen zugedeckt, das Präparat mit Paraffin oder Wachs verklebt und sofort untersucht. Zunächst fällt bei dieser Untersuchungsmethode eine grössere Körnigkeit aller Elemente des Knochenmarkes auf, mit Ausıahme der rothen Blutkörperchen. Jene homogenen Bildungen, wie sie oben unter 2 und 4 , d. h. als gefärbte und blasse bomogene Zellen, beschrieben wurden, treffen wir hier gar nicht an; in gleicher Weise erscheint der Kern in den Uebergangsformen nicht homogen, sondern mehr oder weniger körnig oder gestreift. Man sieht jedoch auch hier gleichmässig körnige Zellen, wobei sie dieselben Veränderungen eingehen, welche oben bei der radiären Kernbildung geschildert wurden. Man beobachtet namentlich auch hier, dass die feinen Körnchen in grössere übergehen, die grösseren Körner sich in regelmässige Reihen ordnen, welche vom Centrum zur Peripherie verlaufen und sich dann in Fäden verwandeln, die sich zum Centrum hin contrahiren. Es ist hier jedoch schwieriger, alle Phasen dieses Prozesses in der Regelmässigkeit an einer und derselben Zelie zu verfolgen, wie dies bisweilen in der Kochsalzlösung gelingt. Doch in einem gewissen Grade ist es auch hier möglich. Dafür kann an verschiedenen Zellen derselbe Prozess vollständig verfolgt werden. Ferner bemerkt man bei dieser Untersuchungsmethode eine Reihe verschiedenster Kernformen, welche durch Abweichungen von ihren typischen, concentrischen und radiären Bildungsweisen bedingt sind. Das Gharakteristische dieser'Abweichungen besteht darin, dass hier aus der Kernsubstanz, vor ihrer Vereinigung zu einem soliden Körper, zunåchst mehrere kleinere, in einem gewissen Grade selbständige 
Körper sich bilden; erst diese haben nächstdem die Neigung, mit einander zusammenzufliessen and einen soliden Körper zu bilden. Diese provisorischen soliden Körper können bald in der Form kurzer dicker Balken, bald als glänzende Tropfen u. s. w. auftreten. Alle diese Körper können in einer und derselben Zelle ohne jeden Zusammenhang und Regelmässigkeit sich finden. Man begegnet jedoch auch Zellen, wo diese Körper gleicbmässiges Aussehen und gleiche Grösse angenommen haben, und zu einander in bestimmten mehr oder weniger regelmässigen Verhältnissen stehen. So beobachtet man nicht selten auffallend regelmässige Sterne mit Strahlen in Form von Dreiecken, deren Basis zur Peripherie und deren Spitze zum Centrum der Zelle gerichtet ist. Die Kernbildung geht bisweilen regelrecht nach dem radiären Modus vor sich, und es entstehen dann auffallend vollendete Sternformen nach Art krystallinischer Figuren.

In den kernhaltigen rothen Zellen entsprechen das Aussehen des Kernes und dessen weitere Modificationen mehr oder weniger den so eben in den Zellen mit gleichmässiger Körnigkeit beschriebenen. Der runde Kern erscheint, wie oben gesagt, nicht homogen, wie in der Kochsalzlösung, sondern man erkennt in demselben stels die Körner und Streifen, bisweilen beides gleichzeitig. Während der weiteren Veränderungen offenbart die Kernsubstanz dieselbe Tendenz, wie sie bei den körnigen Zellen beobachtet wurde, d. h. sie zerfällt zunächst in eine Reihe mehr oder weniger voluminöser Körper, welche nachber das Bestreben baben, zusammenzufliessen. Am Kern sieht man dabei gewisse Eigenthümlichkeiten, wie sie bei Anwendung der Kochsalzlösung nicht beobachtet wurden. Dort sah man nie Kernkörperchen, hier dagegen können die glänzenden Tropfen, welche im Innern des Kernes sich bilden, selbstverständlich nur als Kerakörperchen gedeutet werden. In der Kochsalzlösung beobachtet man niemals eine Continuitätsverletzung des Kerncontours, hier jedoch sieht man bisweilen, dass der Contour sich verdickt und dabei an einigen Stellen springt. Es kommt vor, dass die ganze Kernsubstanz von diesem Verdiekungsprozess betroffen wird; dann erscheint der Kern in Form eines glänzenden Ringes, dessen Inneres binsichtlich Färbung und Lichtbrechungsvermögen mit dem Protoplasma identisch ist.

Dieser Ring kann unverändert bleiben, oder ebenfalls springen, 
wonach die einzelnen Theile desselben auseinandergehen und unter verschiedenen Winkeln sich $\mathrm{zu}$ einander stellen in Form kurzer, dicker Balken, welche schliesslich die Neigung haben, zusammenzufliessen.

In den 8-förmigen Zellen findet man ausser den runden, mehr oder weniger körnigen oder fächerigen Kernen dieselben auch in Form von dicken Balken, in jeder Zellenhälfte quer zur Längsaxe der Zelle gelegen. Beide Balken stehen mit einander in Verbindung durch körnige oder glatte Fäden, welche sich durch die ganze Uebergangsstelle der sich theilenden Zelle hinziehen. Nach einiger Zeit reissen diese Fäden, contrabiren sich zu den Balken hin und fliessen mit diesen zusammen, so dass die Balken schliesslich noch dicker, stark glänzend und ohne irgend welche Spuren ihres früheren Zusammenhanges mit einander erscheinen. Ferner sieht man in den Hälften der sich theilenden Zelle Körner, welche sich in der Weise gruppiren, dass eine Kranzform entsteht. Diese Kränze sind unmittelbar an den am meisten von einander entfernten Polen der Zelle gelegen. Der Kern der gewöhnlichen Markzellen bietet dieselben Eigenthümlichkeiten dar, wie wir sie bei der Untersuchung in einer Kochsalzlösung kennen gelernt haben. Er besitzt ebenfalls einige Kernkörperchen und einen verdickten Contour, ist rund, oval oder hat eine Nierenform. Doch auch hier, ohne Zusatz von Reagentien, sieht man den Kern in den gewöhnlichen Markzellen in bereits fertiger Form, man beobachtet niemals seine Bildung und fächerigen Bau.

Die kleinsten blassen Elemente bei der Untersuchung des Knochenmarkes im eigenen Plasma sind zunäcbst mit einigen Strichen besetzt, welche Fächer bilden, die unmittelbar neben einander liegen. Diese Strichelung verliert sich jedoch bald; alsdann verwandelt sich das Element in ein glänzendes homogenes Kügelchen. Eine umgebende Membran wird nie beobachtet.

Untersucht man ein frisches Präparat in der Kochsalzlösung und fügt man einen Tropfen wässeriger Lösung von Methylviolett binzu, so bemerkt man in einiger Entfernung von dem Rande, an welchem die Färbung begann, und bei allmählicher Einwirbung des Färbemittels folgende Erscheinungen: Die Kerne der Uebergangsund blassen Zellen büssen zunächst ihre Zeichnung ein, werden homogen und blähen sich ein wenig auf. Das Protoplasma der 
Uebergangszellen entfärbt sich daher rasch und wird durchsichtig, der Kern dagegen nimmt die violett-blaue Farbe an und schrumpft darauf bedeutend zusammen. Bei weiterer und noch langsamerer Einwirkung der Farbstofflösung sieht man die Zellen der zweiten Gruppe, d. h. kernlose gefärbte Zellen rasch ihr Hämoglobin verlieren und sofort in toto sicb färben, wonach der Kern zusammenschrumpft und schliesslich im durchsichtigen Protoplasma liegt. Besitzen die Zellen dieser Gruppe die zwei Contouren, so bemerkt man die Blaufärbung nur in der Gegend des inneren Contours. Ist endlich die Strömung der Farbstoftlösung eine so schwache, dass die rothen Blutkörperchen ibren Ort nicht verlassen, so beobachtet man, dass bei weitem nicht alle Blutkörperchen ein gleiches Verhalten der Farbstofflösung gegenüber haben. Sie alle nehmen eine Kugelgestalt an, die einen werden jedoch blass, verlieren allmählich ihre Hämoglobinfärbung und bleiben schliesslich absolut untingirt mit kaum bemerkbaren peripherischen Contourer. Andere Blutkörperchen nehmen anfangs beim Annähern der Farbstofflösung eine violettrothe Farbe an. Diese Färbung schwindet jedoch bald, und statt ibrer sieht man in dem Körperchen ausserordentlich feine, fast staubartige Körnchen, die energische moleculäre Bewegungen ausführen. Diese tanzenden staubförmigen Theilchen fliessen dabei zu etwas grösseren Körnchen zusammen, die letzteren färben sich violettblau, die Bewegungen bören auf, und die Körnchen fixiren sich an einer bestimmten Stelle der Zelle. Das Endresultat ist ein entfärbtes rothes Blutkörperchen, gleichmässig mit violett-blauen Körnchen und hellen Zwischenräumen ausgefüllt. - Hat die Bewegung der Farbstoffflüssigkeit aufgehört, so bemerkt man an der Grenze des gefärbten Gesichtsfeldes im ungefärbten Menstruum nach einiger Zeit, dass in den kernhaltigen rothen Zellen der Kern eine gesättigte violett-blaue Farbe angenommen hat, das Protoplasma dagegen absolut untingirt geblieben, ist, ohne sogar den Farbenton seiner Hämoglobinfärbung eingebüsst zu haben. In den gewöhnlichen Markzellen baben sich der Kern und das körnige Protoplasma gefärbt; die rothen Blutkörperchen jedoch kann man in allen Uebergangsstadien von totaler violetter Färbung bis zur Körnigkeit antreffen. Letztere, die Körnigkeit, kann man jetzt genauer studiren. Bei Bewegungen der Schraube überzeugt man sich, dass die Körnchen gleichmässig in allen Flächen des Kügelchens verbreitet sind. 
Zwischen den einzelnen Körnchen gelingt es bisweilen, verbindende Fädchen zu erblicken, welche gleich den Körnchen gefürbt sind. Die Grösse der Körnchen ist in der Regel gleich, wenngleich man bisweilen mehrere Körnchen zusammenfliessen und dadurch die Grösse eines kleinen Kernkörperchens erreichen sieht. In verschiedenen Körperchen ist die Körnigkeit in verschiedenem Grade ausgesprochen: in einigen Zellen ist gleichsam die ganze Zelle gleichmässig ausgefüllt, in anderen erblickt man nur wenige einzelne Körnchen - 2-3 in einer Zelle, im letzten Falle gewöhnlich unweit der Peripherie gelegen. Zwischen diesen Extremen finden sich alle Uebergangsstufen. Untersucht man ohne Zusatz von Reagentien unter Einfluss von Methylviolett, so sieht man die Figurationen des Kernes in den Uebergangs-, auch blassen Zellen ausserordentlich deutlich gefärbt. Doch auch hier muss die Beobachtung an einer Stelle ausgeführt werden, die von jenem Rande, an dem die Farbstoffflüssigkeit zugeführt wurde, weiter entfernt liegt, und zwar im ungefärbten Gesichtsfelde, einige Zeit nach dem Färben des Präparats. Bei diesen Gautelen gelingt es genau, die Figurationen des Kernes in den Uebergangsformen zu sehen, ohne dass die Hämoglobinfärbung selbst ihres Farbentons verlustig gegangen wäre*).

Bei der Untersuchung des Knochenmarkes in verschiedenen Zeiträumen nach dem Tode des Thieres sieht man im Vergleich zum vollkommen frischen Zustande gewöhnlich folgende Ejgenthümlichkeiten: Nach Verlauf von 4-6 Stunden sind die Kerne in den Uebergangszellen prononcirter und, wie bereits oben gesagt, schwanken sie in ihrer Grösse weniger, als sofort nach dem Tode des Thieres. Homogenen Zellen der 2. und 4. Gruppe begegnet man in der Regel gar nicht. Entsprechende Veränderungen bemerkt man auch an den rothen Blutkörperchen. Sie haben ihr mattes Aussehen bedeutend verloren, ihre Hämoglobinfärbung ist viel deutlicher und man begegnet ihnen jetzt vorzüglich in 2 Formen: in der Kugelund Mützenform. Untersucht man das Mark 24 Stunden nach dem Tode des Thieres, so beobachtet man Folgendes: die rothen Blutkörperchen besitzen meist die Kugelform, selten die Mützenform;

*) Verschiedene Gattungen von Methylviolett haben etwas verschiedene Wirkung. So erhiejt ich in Breslau durch Methylviolett eine auffallend zarte violettblaue Färbung der unreifen rothen Blutkörperchen; das Petersburger Methylviolett dagegen fărbte dieselben Elemente violett mit einem Strich in's Rothe. 
sie haben einen gewissen Glanz angenommen, ihre Färbung ist gesättigter, an Grösse scheinen sie bedeutend abgenommen zu haben. Zugleich sind sie so wenig empfindlich gegen äussere Einflüsse geworden, dass sie auf Zusatz $\frac{3}{4}$ procentiger Kochsalzlösung nicht zusammenschrumpfen und ihre Kugelform nicht aufgeben. Die kernhaltigen Zellen sind ebenfalls kugelförmig; ihr Protoplasma ist ebenfalls glänzender geworden und intensiver gefärbt; desgleichen fällt ihre Grössenabnahme auf. Ihr Kern ist klein, glänzend, bisweilen vollkommen homogen, bisweilen findet sich Fächerung und Körnelung. Kerne von weniger als $2-3 \mu$ Grösse trifft man bier ebenso wenig, wie in den Uebergangszellen des frischen Markes. Statt der excentrischen Lage begegnet man jetzt in vielen Zellen der peripherischen Lage des Kernes, so dass derselbe mit einem grösseren oder kleineren Theil ausserhalb der Zelle gelagert ist. In einigen Fällen endlich sieht man ihn ganz und gar ausserhalb der Zelle liegen. Der Zusammenhang zwisehen Zelle und Kern ist dabei oft optisch nicht zu entdecken, man erschliesst ihn nur aus den entsprechenden Bewegungen, wenn solche Zelle im Präparat zu schwimmen beginnt. Zwingt man sie jetzt, ibren Weg durch die engen Zellenzwischenräume zu nehmen, so beobachtet man auch beim längeren Zusehen gewöhnlich nicht eine Trennung des ausgetretenen Kernes vom Protoplasma. An den gewöhnlichen Markzellen bemerkt man weder amöboide Bewegungen noeh das Streben in Haufen zusammenzufliessen: gewöhnlich liegen alle Elemente des Markes ziemlich regelmässig im Präparat vertheilt.

Lässt man auf ein solches Präparat Picrocarmin einwirken, so bemerkt man, dass bei langsamer Einwirkung des Farbstoffstromes das Protoplasma der kernhaltigen rothen Zellen zu verschwimmen und seine Contouren zu verlieren beginnt. Darauf, im bereits farbigen Gesichtsfelde, bläht sich der Kern auf; auch er zerfliesst darnach, durchbricht gleichsam das Protoplasma und ergiesst sich nach aussen, wobei er augenblicklich die rothe Farbe annimmt. An der Zelle, aus der der Kern ausgewandert ist, bemerkt man, dass, indem das Protoplasma mehr und mehr ein verschwommenes Aussehen annimmt, der Kern in dasselbe hineinzudringen beginnt, bis er schliesslich vollkommen hineingewandert ist. Die weiteren Veränderungen sind dieselben, wie im vorhergehenden Falle. 33procentige Aetzkalilösung vernichtet in einem Moment sowobl den Kern 
als das Protoplasma, auch wenn der Kern sich ausserhalb der Zelle befindet.

Gehen wir jetzt zur Analyse der oben beschriebenen Bilder und Erscheinungen über.

Hinsichtlich der rothen Blutkörperchen wurde bemerkt, dass ihre Grösse im Knochenmark annähernd innerhalb derselben Greuzen schwankt, wie im Blute. Dies bezieht sich sowohl auf das normale, als auch auf das pathologisch veränderte Knockenmark. So trifft man bei Anämie resp. bei Hydrämie auffallend grosse rothe Blutkörperchen im Knochenmark an, doch ganz ebenso grossen Blutkörperchen und überhaupt einer ebensolchen Ungleichmässigkeit hinsichtlich ihrer Grösse begegnet man dann auch im Blute, worüber bereits früher in der Literatur (Hayem) Erwähnung geschah, und wovon ich mich auch bei meinen Untersuchungen an Leichen habe überzeugen können. Ein gleiches Verhältniss binsichtlich der Grösse der rothen Blutkörperchen im Blute und in den blutbildenden Organen findet man bei Embryonen. Ich erwähne die Grösse der rothen Blutkörperchen, weil bei Rindfleisch ( ${ }^{7} \mathrm{~S} .28$ ) von "verschiedener Grösse" derselben die Rede ist, wonach man glauben könnte, dass diese Grössenschwankungen im Knochenmark grösser sind als im Blute, während dieses factisch nicht beobachtet wird. Die oben beschriebenen homogen gefärbten Zellen der zweiten Gruppe können ja nicht $z u$ den rothen Blutkörperchen gerechnet werden.

Wir haben ferner gesehen, dass die rothen Blutkörperchen im vollkommen frischen Mark gegen alle äusseren Einflüsse und Reagentien ausserordentlich empfindlich sind, so dass sie sogar nach Zusatz von 0,5 procentiger Kochsalzlösung eckig werden, dass ihre Hämoglobinfärbung hierbei nicht scharf ausgesprochen ist, und dass sie ein mattes Aussehen haben. Wir haben ferner constatirt, dass sie schon in der Kochsalzlösung meistentheils die Kugelform annehmen, und dass hierbei ihre Hämoglobinfärbung und ihr Lichtbrechungsvermögen stärker werden. Auffallendere Veränderungen fanden wir an denselben ferner bei Untersuchung des Markes 24 Stunden nach dem Tode des Thieres. Hier fanden wir schon fast alle Blutkörperchen von Kugelform mit einem bedeutenden Glanz, mit scharf ausgesprochener Hämoglobinfärbung und einem leichten Uebergang des 
gelben Tons in's Orangefarbene. Am meisten auffallend war jedoch ihre Volumsabnahme, ganz analog der Volumsabnahme der kernhaltigen rothen Zellen. Um sich von der Identität dieser Veränderungen der rothen Blutkörperchen im Knochenmark und im Blute zu überführen, kann man in denselben Zeiträumen nach dem Tode des Thieres Blut wie Mark untersuchen. Die biconcaven Scheiben erscheinen im frischen Blut matt, schwach gelb, mit einem Stich in's Grüne. Einige Stunden nach dem Tode des Thieres finden wir oft die Mützenform. Endlich nach 24 Stunden hat die Mehrzahl die Kugelform angenommen mit einem bedeutenden Glanz, deutlicher Gelbfärbung, welche in's Orangefarbene übergeht, und mit auffallender Volumsabnahme. Es ist klar, dass eine biconcave Scheibe beim Uebergange in die Kugelform eo ipso in ihren Dimensionen abnehmen muss; dass hier diese Abnahme jedoch keineswegs von der einfachen Formveränderung abhängt, dafür spricht die auffallende Volumsabnahme der kernhaltigen rothen Zellen: bei diesen beobachtet man sowohl sogleich nach dem Tode, als auch nach 24 Stunden die gleiche kuglige Form, und dennoch erscheinen sie nach 24 Stunden auffallend kleiner in ihrem Volumen.

Sämmtliche Leichenerscheinungen an den rothen Blutkörperchen manifestiren sich somit als Formveränderung, Steigerung der Hämoglobinfärbung, des Lìchtbrechungsvermögens und der Volumsabnahme. Es leuchtet ein, dass der bauptsächlichste Grund aller dieser Veränderungen in einer Dichtigkeitszunahme des Protoplasma der rothen Blutkörperchen zu suchen ist, und dass die Volumsabnahme, die Steigerung des Farbentons und des Lichtbrechungsvermögens, ja vielleicht auch die Gestaltveränderungen nur als Begleiterscheinungen anzusehen sind, welche aus der Haupterscheinung, der Verdichtung des Protoplasma, resultiren. Die Ursache dieser Haupterscheinung ist uns nicht bekannt, wir wissen nicht, wodurch diese unvermeidliche Verdichtung des Protoplasma im Leichenzustande bedingt wird, die ibrerseits unvermeidlich zur Verstärkung des Farbentones und Lichtbrechungsvermögens führt, für uns ist aber von Wichtigkeit, eine gemeinsame Ursache für viele einander begleitende Erscheinungen zu finden. Es ist uns ferner bekannt, und dieses wird sich auch aus der nachfolgenden Analyse wiederum ergeben, dass das Protoplasma der rothen Blutkörperchen mit dieser Ejgenthümlichkeit, im Leichenzustande sich zu verdichten, 
in der Reihe der verschiedenen zusammengesetzten Eiweisskörper nicht vereinzelt dasteht.

Wenden wir uns somit zur Analyse der Ersebeinungen, welche von uns in den Zellen der 2. und 4. Gruppe beobachtet wurden, d. h. der gefärbten und blassen Zellen, welche im vollkommen frischen (Mark) Zustande keinen Kern aufweisen. Es wurde bereits constatirt, dass sie nur in der Kochsalzlösung homogen erscheinen; untersucht man das Mark im eigenen Plasma, so erscheinen sie gleichmässig fein oder grobkörnig. Am zweiten Tage nach dem Tode des Thieres begegnet man ihnen gar nicht mehr, da dann ausser den rothen Blutkörperchen alle Markelemente mit Kernen versehen sind. Wir haben ferner gesehen, dass auch in der Kochsalzlösung an Stelle des homogenen Aussebens nach einiger Zeit ein körniges Aussehen tritt; letzteres geht in eine radiäre Fädchenzeichnung über, die Fädchen contrahiren sich allmählich zum Centrum, wo sich schliesslich ein Kern in Form eines soliden Körpers bildet. Doch diese, von uns als radiär bezeichnete Kernbildung wird in der Kochsalzlösung nicht sofort nach Anfertigung des frischen Präparates, sondern erst einige Zeit später beobachtet. In der ersten Zeit dagegen beobachtet man nur den concentrischen Kernbildungsmodus, welcher darin besteht, dass nach Verbreiterung des peripherischen Contours in einem der Zellensegmente die Bildung zweier Contoure beobachtet wird, von denen der innere dem Kern angehört. Letzterer contrahirt sich darauf zu dem Theil der Zellenperipherie hin, wo die Trennung des peripherischen Contours von dem Contour des Kernes am längsten auf sich warten liess. Wir haben scbliesslich eine Menge von Abweichungen von den typischen Bildungsweisen bei der Kernbildung kennen gelernt, hauptsächlich bei Untersuchungen des Präparates ohne Zusatz von Reagentien. Unter dieser Unzahl von Erscheinungsweisen, in denen die Zellen der 2. und 4. Gruppe oder richtiger gesagt, ihre Kerne auftreten, haben wir also zu entscheiden, welcher Zustand als der vitale anzusehen ist, und wodurch jene Formverschiedenheiten des Kernes bedingt sind.

Auf den ersten Theil der Frage, d. h. den primären vitalen Zustand der Zelle resp. des Kernes sind 4 Antworten möglich, denn wir kennen 4 typische Formen, in welchen wir der Kernsubstanz in den von uns beschriebenen Zellen begegnen: 1) in Gestalt eines 
soliden Körpers, welcher in der Zelle liegt, 2) in Sternform mit faserigen Strahlen, welche bis zur Peripherie der Zelle reichen, 3) in Form von Körnern, welche gleichmässig die ganze Zelle ausfüllen und 4) im formlosen Zustande, wenn die Kernsubstanz gleichmässig diffus in der ganzen Zelle verbreitet ist. Bisher wurde angenommen, dass die Kerusubstanz in den Uebergangsformen der Säugethiere nur im ersten Zustande, d. h. in Form eines in der Zelle liegenden Körpers auftritt (Kölliker, Neumann, Rindfleisch u. A). Da man aus dieser Form jedoch z. B. die Strahlenform, von den anderen Kernformen gar nicht zu reden, nicht ableiten kann, da die Strahlenform eben unter unseren Augen in einen soliden Körper übergeht, so müssen wir diese letztere Gestalt, als eine später entstandene ansehen, und uns zur Strahlenform wenden. Wenngleich die Strahlenform des Kernes an den Uebergangsformen der Säugethiere bisher nicht beschrieben ist, so ist sie doch bereits von Flemming $\left.{ }^{23} \mathrm{~S} .395\right)$ in den rothen Blutkörperchen des Frosches und von Peremeschko ${ }^{15}$ in den rothen Blutkörperchen der Embryonen von Bufo variabilis und Triton bei ibrer Theilung gesehen. Aus dieser Gestalt kann man mit Leichtigkeit die erste Form herleiten: die Strahlen contrahiren sich schliesslich zum Centrum und bilden dort einen soliden Körper. Man kann aus ihr jedoch nicht die gleichmässige Körnigkeit der Zelle erklären. Der dritte Zustand der Kernsubstanz in den Uebergangsformen ist bisher noch nicht beschrieben, und dennoch kann er ohne Schwierigkeit im ganz frischen Mark, besonders wenn es im eigenen Plasma untersucht wird, beobachtet werden. Wir haben gesehen, dass die einzelnen Körner sich gewöhnlich in regelmässige radiäre Reihen stellen und Fasern bilden, folglich kann man aus der Körnchenform die zwei vorhergehenden herleiten, man kann jedoch aus ihr andererseits das vollkommen homogene Aussehen der Zelle, wo es keinerlei morphologische Form der Kernsubstanz giebt, nicht erklären. Wenn oben erwähnt wurde, dass unter der Einwirkung von z. B. destillirtem Wasser oder 1procentiger Serumlösung von Ammonium chromicum nicht selten der Kern homogen wird, selbst wenn in demselben vorher Körnchen- und Fächerzeichnung beobachtet war, - ja sieht man unter Einfluss des letzteren Reagens die Kerncontouren mit den Zellencontouren zusammenfliessen, und könnte man darnach geneigt sein anzunehmen, dass das von uns beobach- 
tete homogene Aussehen das Resultat etwaiger ähnlicher Einflüsse, folglieh ein aus den anderen Kerngestalten entstandenes Kunstproduct sei, - so wissen wir doch, 1) dass Kochsalzlösung das körnige oder fächerige Aussehen des Kernes, wenn es einmal vorhanden, nicht aufhebt, 2) dass das homogene Ansehen der betreffenden Zellen sofort nach Anfertigung des frischen Präparates beobachtet wird und 3) dass die Zellen der zweiten Kategorie hierbei die Intensität ihrer Hämoglobinfärbung nicht einbüssen. Dieses alles weist darauf hin, dass die homogene Beschaffenheit weder durch den Leichenzustand der Zelle, noch durch Kochsalzlösung, noch durch irgend welche für das Leben der betreffenden Zellen ungünstigen äusseren Verbältnisse bedingt wird. Beobachtet man dagegen direct das Entstehen der Körnehen in der homogenen Zelle, die in zwei andere Kernformen übergehen, so ist der Schluss gestattet, dass der homogene, kernlose Zustand der blassen und Uebergangszellen den vitalen Urzustand darstellt, und dass alle ubrigen Formen aus diesem durch Leichenveränderungen in der Zelle entsteheu.

Es erïbrigt noch, den zweiten Theil der Frage zu lösen, d. i. festzustellen, wodurch die verschiedenen Formen des Kernes beim Uebergang in den Leichenzustand bedingt werden. Wie bereits oben heschrieben, begegnet man bei Untersuchung eines frischen Präparates in Kochsalzlösung neben vollkommen homogenen blassen Zellen nicht selten Zellen derselben Kategorie, nur mit Erweiterung des peripherischen Contours, wobei die Zelle, mit Ausschluss dieser Erweiterung, homogen bleibt, d. b. man siebt weder Strichelung noch Körneling. Wir wissen bereits, dass diese Erweiterung daher kommt, dass bier 2 Contouren neben einander liegen und der innere dem Kern angehört. Dabei überzeugt man sich, dass während dort in den Zellen mit vollkommen homogenem Aussehen die Kernsubstanz ganz gleichmässig die ganze Zelle ausfüllt, hier in den Zellen mit Erweiterung des peripherischen Contours dagegen die Kernsubstanz ein der Grösse nach kaum bemerkbar kleineres Volumen einnimmt, was nur dadurch kenntlich wird, dass der Contour des Kernes mit dem Zellencontour nicht zusammenfällt, sondern unmittelbar neben demselben gelagert ist. Bei weiterer Beobachtung sieht man, dass der Kerncontour sich von dem peripherischen Contour immer weiter entfernt, d. h. die Kernsubstanz 
beginnt ein immer kleineres Volumen einzunehmen, und erlangt dabei ein grösseres Lichtbrechungsvermögen, ohne ihr homogenes Aussehen zu verlieren. Mit einem Wort, wir haben im Grunde dieselbe Erscheinung vor uns, die wir bei der Analyse der Leichenerscheinungen im Protoplasma der rothen Blutkörperchen kennen gelernt haben, nehmlich die Verdichtung der Kernsubstanz mit Volumsabnahme und Zunahme des Lichtbrechungsvermögens, diesen unvermeidlichen Begleitern der Grunderscheinung, - der Dichtigkeitszunahme. In den rothen Blutkörperchen konnte diese Erscheinung jedoch nicht so deutlich hervortreten, weil das Protoplasma, schon vor der postmortalen Zunahme seiner Dichtigkeit, letztere in einem bedeutend höheren Grade besitzt, als die Kernsubstanz in den Uebergangsund blassen Zellen grossen Kalibers. In den Zellen letzterer Gattung, welche bisweilen eine Grösse von $12 \mu$ erreichen, haben wir einen Kern von 3-4 $\mu$. Da wir nun wissen, dass im vitalen Zustand seine Substanz gleichmässig in der ganzen Zelle ergossen war, so folgt der Schluss, dass der Kern sich im Verbältniss zu seinem vitalen Zustande um das 3-4 fache verkleinert hat. Dieses beobachtet man in den rothen Blutkörperchen nicht, desgleichen nicht in den kleinen Repräsentanten der Uebergangs - und blassen Zellen. In letzteren ist das Quantum der Kernsubstanz annähernd dasselbe, wie in den grossen Repräsentanten derselben Kategorien, und dennoch nimmt sie im vitalen Zustande im Vergleich zu den grossen Zellen einen 2-3 Mal geringeren Raum ein, d. h. sie besitzt eine ebenso viele Mal erhöhte Dichtigkeit; im Leichenzustande der Zelle aber kann in ihr die Dichtigkeitszunahme der Kernsubstanz um ebenso viel weniger scharf hervortreten, als in den grossen Zellen. Ein zweiter Unterschied beim Auftreten einer und derselben Erscheinung im Protoplasma der rothen Blutkörperchen und der Kernsubstanz der Uebergangs - and blassen Zellen beruht in der Zeit des Verdichtungsprozesses. Wir wissen, dass selbst mehrere Stunden nach dem Tode des Thieres im Blute eine Menge von Blutkörperchen in Scheibenform angetroffen werden kant, die ihr mattes Aussehen nicht verloren haben; untersucht man jedoch parallel zu gleicher Zeit das Knochenmark, so findet man alle Uebergangszellen mit Kernen versehen. Dieser Unterschied im Zeitpunkt, wann der postmortale Verdichtungsprozess des gefärbten Protoplasma und der Kernsubstanz beginnt, liefert 
uns den Schlüssel zur Erklärung sehr vieler Facta. Wir wissen jetzt, dass die primäre Verdichtung der Kernsubstanz oder was dasselbe ist, der Anfang der Kernbildung im vitalen Zustande des Protoplasma vorkommt, bei jener flüssig-weichen Consistenz, welche dasselbe während des Lebens besitzt; folglicb überwindet die Kernsubstanz, wenn sie in genügender Menge vorhanden ist, ohne Schwierigkeit jene Hindernisse, welche sich ibr von Seiten des Protoplasma bei ihrem Bestreben, sich zu verdichten, entgegenstellen. In diesem Falle haben wir eine gleichmässige Verdichtung der Kernsubstanz und ihr Zusammenfliessen in eine einzige kugelige Masse vor uns. Morphologisch drückt sich dieser Prozess als Kernbildung nach dem concentrischen Modus aus. Etwas ganz anderes ist es jedoch, wenn das Medium, in welchem die Kernsubstanz ergossen ist, und in welchem sie in einen dichteren Zustand übergehen sollte, selbst sich zu verdichten beginnt, oder mit anderen Worten, wenn im Protoplasmá selbst die "Leichenstarre“ beginnt. Der regelmässige Verlauf des begonnenen Verdichtungsprozesses der Kernsubstanz wird dadurch unvermeidlich gestört und complicirt sich durch Entstehung primärer vereinzelter $\mathrm{Zu}$ sammenflusspunkte, welche erst vermittelst weiterer Combinationen ihrer Lage allmählich zum allgemeinen Zusammenfluss und grösster Verdichtung gelangen, was sich morphologisch als Auftreten von Körnern und Strichelung im grossen homogenen matten Kern ausdrückt. Letzlere Form kann erst nach einiger Zeit durch den glänzenden homogenen Kern ersetzt werden.

Schwache Kochsalzlösung hemmt für einige Zeit den Verdichtungsprozess der Kernsubstanz, daher wird der concentrische Kernbildungsmodus in den Uebergangszellen unter dem Mikroskop selten beobachtet; die Lösung bleibt offenbar in dieser Beziehung ohne Einfluss auf das Protoplasma. Bei Beschreibung der mikroskopischen Beobachtungen wurde bereits erwähnt, dass man in den Uebergangszellen bald nach Anfertigung des Präparates nicht selten eine Reihe verschiedenartiger Formen sieht, welche nachher in die Kugelform iibergehen, bei gleichzeitiger Steigerung der Hämoglobinfärbung des Protoplasma, Verlust des matten Aussehens und gleichsam Verwischtwerdens der Contouren des Kernes. Es ist einleuchtend, dass die Schwächung der Contourzeichnung des Kernes hier dureh Zunahme des Lichtbrechungsvermögens des Protoplasma bedingt wird, und 
dass letztere wiederum von seiner Dichtigkeitszunahme abhängt. Auf diese Weise vollzieht sich nach Sistirung vermittelst der Kochsalzlösung die postmortale Verdichtung der Kernsubstanz in dem schon in gewissem Grade verdichteten Protoplasma, welches dem allgemeinen Zusammenfluss der Kernsubstanz weit mehr Hindernisse entgegengestellt, als im vitalen Zustande. Daher manifestirt sich hier der Prozess, statt einer gleichmässigen Verdichtung durch Bildung einer Menge primärer, gewissermaassen vereinzelter Zusammenflusscentren, morphologisch durch Auftreten der Trübung in einer ganz homogenen Zelle. Diese feinen Centren fliessen allmählich unter einander zusammen und bilden schliesslich grössere Theilchen, was sich durch Auftreten grösserer oder kleinerer Körnchen in der Zelle zu erkennen giebt. - Bisher war nur von der Bildung partieller Zusammenflusscentren die Rede, welche sich durch Auftreten einer gleichmässigen Körnelung in der ganzen Zelle kundgiebt. Allein das Bestreben, zusammenzufliessen, beschränkt sich nicht auf diese vereinzelten Centren: einzelne Körner stellen sich in Reihen, vereinigen sich unter einander und bilden dadurcb Fäden, welche regelmässig radiär vom Centrum zur Peripherie verlaufen. Es ist klar, dass bei einer derartigen Lage der Körnchen, wie bei der Fädchenbildung, das Bestreben der Kernsubstanz, zusammenzufliessen, sich viel mehr verwirklichen kann, als bei der gleichmässigen Körnigkeit, wo jedes einzelne Körnchen für sich jene Hindernisse überwinden muss, welche sich ihm von Seiten des verdichteten Protoplasma entgegenstellen.

In der Leiche finden sich Bedingungen, welche die concentrische Kernbildung begünstigen. Mit diesem Bildungsmodus complicirt sich nachher bei schon begonnener Verdichtung des Protoplasma der radiäre Modus; daher trifft man schon einige Stunden nach dem Tode des Thieres in allen blassen und Uebergangszellen einen Kern mit einem runden Contour, - ein deutlicher Beweis dafür, dass seine Bildung nach dem concentrischen Modus ihren Anfang nahm, allein zugleich findet man Fächerbildung und Körnchen als Zeichen dafïr, dass von Seiten des Protoplasma mehr oder weniger Hindernisse sich in den Weg gestellt haben.

Dieses bezieht sich jedoch auf ein erwachsenes gesundes Thier. Bei Embryonen begegnet man Abweichungen, welche hauptsächlich als verminderte Neigung zur Leichenverdichtung, nament- 
lich in der Kernsubstanz ibren Ausdruck finden. Daher ist es am geeignetsten, die gefärbten homogenen Zellen in den Blutbildungsorganen der Embryonen zu untersuchen. Im Knochenmark neugeborener Thiere ist das Bestreben der Kernsubstanz sich zu verdichten schon bedeutend mehr entwickelt; dennoch trifft man auch hier weit mehr kernlose, vollkommen homogen gefärbte Zellen an, als beim erwachsenen Thiere. Bei diesem sind bisweilen schon fünf Minuten nach dem Tode alle Uebergangs- und blassen Zellen mit Kernen versehen.

Es wurde so eben gesagt, dass in der Leiche die Möglichkeit zur Kernbildung nach dem concentrischen Modus in den Uebergangszellen gegeben ist, weil das Protoplasma einige Zeit hindurch seine vitale Dichtigkeit bewahrt. Wir sind jedoch im Stande, diese Bedingungen der Kernbildung zu modificiren, indem wir künstlich Verdichtung aller Elemente des Knochenmarks in seinem frischen Zustande hervorrufen; dieses kann sehr leicht durch Verdunstenlassen eines Tropfens Marksaft geschehen. Ganz dasselbe erreicht man, wenn man das Präparat aus vollkommen frischem Knochenmark ohne Zusatz von Reagentien anfertigt und im eigenen Plasma untersucht. Bringt man einen Tropfen Mark aus der Knochenhöhle auf's Objectglas, so kommt unzweifelhaft Verdunstung zu Stande und damit zugleich Verdichtung des Plasma und aller Elemente des Knochenmarks, da ihr Imbibilionsquantum vermindert wird. Ausser dem physiologischen Bestreben der Kernsubstanz zur Verdichtung kommt hier noch die Wirkung der Imbibitionsverminderung hinzu. Die Kernsubstanz ist noch energischer bestrebt, ein kleineres Volumen einzunebmen und zusammenzufliessen, sie begegnet aber einem Widerstand von Seiten des Protoplasma, das sich ja in Folge der Verdunstung verdichtet hat, - so entstehen die Zellen mit gleichmässiger Körnigkeit sofort nach Anfertigung des Präparates aus vollkommen frischem Mark. Auch der homogene Kern, welcher nach dem concentrischen Modus sich zu bilden begonnen hatte, wird körnig oder fächerig.

Die Körnchen können in Fäden übergehen, diese in einen steruförmigen Kern u. s. w., mit einem Worte, auch hier könnte die Kernbildung nach dem typischen radiären Modus vor sich gehen; die selbständige Leichenverdichtung des Protoplasma bringt jedoch eine solche Menge von Hindernissen mit sich, ruft so viele $\mathbf{A b}$ - 
weichungen von den typischen Kernbildungsweisen hervor, dass es mit Hinsicht auf diese vielen Abweichungen schwer fullt, sich von dem Vorhandensein bestimmter Bildungsweisen ein Bild zu machen. Als allgemeiner Charakter dieser Abweichungen kann, wie bereits oben bei Schilderung der Beobachtungen gesagt, bezeichnet werden, dass die primären, oft unregelmässigen Zusammenflusscentren verschiedenster Art sich isoliren. Dadurch entsteht eine Reihe von Tropfen und Balken, welche bald unter einander in einem mehr oder weniger regelmässigen Zusammenhange stehen, bald - was bäufiger der Fall ist, - ohne jegliche Ordnung und Symmetrie in der Zelle zerstreut liegen. In den Kernen mit runden Contouren findet dieselbe Erscheinung ihren Ausdruck als Auftreten von Zwischenwänden, von Tropfen in Form yon Kernkörperchen, als Verdickuug der Contouren, Springen derselben u. s. w.

Alle die beschriebenen Erscheinungen und namentlich der radiäre Kernbildungsmodus werden in denjenigen Zellen beobachtet, welche ein gewisses quantitatives Verhältniss von Kernsubstanz zum Protoplasma aufweisen können. Wir hatten bereits Gelegenheit, zu erwähnen, dass in den blassen und Uebergangszellen kleinen Kalibers der concentrisehe Bildungsmodus zwar beobachtet werden kann, dass jedoch die Volumsabnahme der Kernsubstanz nicht recht zum Ausdruck kommen kann. Am besten kann auch der concentrische Bildungsmodus in den grossen Zellen beobachtet werden. Der radiäre Bildungsmodus wird nur in grossen Zellen, annähernd von $10-12 \mu$, beobachtet.

Ueberschreitet diese quantitative Verminderung der Kernsubstanz im Verhältniss zur Protoplasmamenge jedoch eine gewisse Grenze, so kann dies auf das Streben der Kernsubstanz nach Verdichtung nachtheilig einwirken. Bei Schilderung unserer Beobachtungen wurde bereits erwähnt, dass das geringste Volumen der Kerne in den blassen und Uebergangszellen eines gesunden Thieres annähernd $2-3 \mu$ beträgt, und diese dabei glänzend und homogen sind. Kerne geringeren Volumens beobachtet man gewöhnlich in den Uebergangszellen nicht. Jene Hindernisse, welchen die Kernsubstanz von Seiten des Protoplasma bei ihrem Bestreben, sich zu verdichten, begegnet, und welche von ihr ohne Schwierigkeit überwunden werden, so lange sie in einer gewissen Quantität vorhanden ist, werden unüberwindlich, sobald die Kernsubstanz 
über ein gewisses Maass hinaus verdünnt ist, wenn ihre Molekeln gegenseitig nicht eine so starke Anziehungskraft ausüben können, um die Schwierigkeiten von Seiten des Protoplasma, bei dessen normaler vitaler Dichtigkeit, zu überwinden. Wir sind im Stande, das Medium, in welchem sie sich im Gleichgewichtszustande befinden, zu verdünnen, wenn wir zum Präparat destillirtes Wasser oder noch besser eine Lösung von Methylviolett hinzufügen. Die Molekeln der Kernsubstanz verlieren dadurch ihr Gleichgewicht, führen eine Reihe energischer Bewegungen aus, und vereinigen sich in Körnchen; das Streben zum Zusammenfliessen ist hier jedoch gehemmt: die einzelnen Theilchen, die sich gebildet hatten, sind durch zu weite $\mathrm{Zwischenräume} \mathrm{von} \mathrm{einander} \mathrm{getrennt,} \mathrm{sie} \mathrm{liegen}$ ausserhalb der Sphäre ihres gegenseitigen Anziehungsvermögens, und so haben wir statt eines einzigen Kernes gleichmässige Körnelung des ganzen Körperchens.

In der Leiche trifft man bisweilen diese Verdünnung des Mediums, in welchem die Kernsubstanz ergossen ist, als Folge pathologischer Veränderungen des Blutes. So begegnet man im Mark von Hydrämikern nicht selten Uebergangszellen mit auffallend kleinen Kernen, bisweilen gleichsam aus $2-3$ Körnern bestehend. Der Grund ist klar: die vermehrte Imbibition des Protoplasma setzt seine Dichtigkeit herab, und dieses ist unvermeidlich verbunden mit Verminderung des Widerstandes gegen die Verdichtung der Kernsubstanz.

Die Analyse der kernhaltigen rothen Zellen kann uns keine Schwierigkeiten darbieten. Ihr allgemeines Aussehen ist längst der Wissenschaft bekannt und von den Autoren mit grosser Uebereinstimmung beschrieben. Kölliker ${ }^{9}$ Neumann ${ }^{1}$, Bizzozero ${ }^{6}$, Cohnheim ${ }^{17}$, Osler ${ }^{21}$, Orth und Litten ${ }^{19}$, Rindfleisch ${ }^{7}$ und Andere verstanden unter dieser Form eine runde Zelle mil gefärbtem homogenem Protoplasma und farblosem Kern. Die Mehrzahl der Autoren stimmt darin überein, dass der Kern farblos ist, und nur bei Beschreibung gewisser pathologischer Fälle (Cohnheim ${ }^{17}$ ) finden sich Andeutungen, dass er gefärbt war. Wir wissen bereits, dass der Kern gefärbt oder ungefärbt erscheint, je nach der Dichtigkeit, welche seine Substanz im Vergleich zur Dichtigkeit des gefärbten Protoplasma besitzt. Ist er voluminös und befindet sich seíne Substanz im verdünnten Zustande, so scheint er mitten. 
im gefärbten, normal dichten Protoplasma ebenfalls gefärbt zu sein. Ist dagegen das Volumen des Kernes um ein Bedeutendes vermindert, so wird es stets deutlicher, dass derselbe nicht gefärbt ist.

Aus der vorhergehenden Analyse wissen wir bereits, dass diese Form nicht die ursprüngliche Gestalt ist, dass sie den Uebergangszellen im vitalen Zustande nicht eigenthümlich ist, dass sie vielmehr den Leichenzustand der gefärbten Zellen vorstellt und durch die Neigung der Kersubstanz zur Verdichtung sofort nach dem Tode des epwachsenen Thieres zu Stande kommt.

Die excentrische Lage des Kernes in den Uebergangszellen wird von den meisten Autoren, welche diese Form beschrieben, zugegeben; mit besonderer Betonung sprechen davon Neumann ( ${ }^{1} \mathrm{~S} .73$ ) und Rindfleisch ( ${ }^{7}$ S. 23). Letzterer sieht darin eine sehr günstige Bedingung zur Emigration des Kernes, aber eine Erklärung dieser Erscheinung liefert er ebenso wenig, wie die anderen Autoren. Unsere Beobachtungen über die Kernbildung in den Uebergangs- und blassen Zellen, nach dem concentrischen Modus, wobei der Kern sich zu dem Theile der Zellenperipherie zusammenzieht, an welchem die Contourtheilung am spätesten erfolgt, machen die excentrische Lage des Kernes in den Uebergangszellen erklärlich; und da wir nun in der Leiche eines gesunden Thieres die Bedingungen gefunden haben, welche die Kernbildung nach diesem Modus begünstigen, so ist nicht za verwundern, dass wir kürzere oder längere Zeit nach dem Tode des Thieres hauptsächlich oder sogar ausnahmslos die excentrischie Lage des Kernes antreffen, besonders wenn wir die postmortale Verdichtung des Protoplasma selbst dabei erwähnen.

Wir sind somit zur Auswanderung des Kernes aus den bernhaltigen rothen Zellen gelangt. In den rothen Blutkörperchen des Frosches ist dieser Prozess, als Leichenerscheinung, den Histologen scbon längst bekannt (Kölliker ${ }^{10}$ S. 625); mit Rücksicht auf die kernhaltigen rothen Zellen der Säugethiere ist er erst im vorigen Jahre von $R$ indfleisch beschrieben, wenngleich der äusserst peripherischen Lage schon bei Orth ( ${ }^{20}$ S. 102) in seinem Lehrbuch Erwähnung geschieht. Wir waren bemüht, diesen Prozess hinreichend vollständig zu verfolgen. Wir überzeugten uns, dass unmittelbar nach dem Tode des Thieres der Kern niemals in der Austrittsperiode beobachtet wird, dass die ersten vereinzelten Fälle 
von ausgesprochen peripherischer Lage desselben erst nach Verlauf von 1-2 Stunden nach dem Tode des Thieres gesehen werden; nach 24 Stunden dagegen beobachten wir nicht selten nicht nur eine deutliche peripherische Lage des Kernes, sondern auch alle Phasen seiner Auswanderung aus der Zelle. Dieser Prozess kann noch künstlich verstärkt werden. So hatte ich einst die frisch ausgeschnittene Rippe eines Kaninchens in Müller'sche Flüssigkeit gebracht und liess sie bei Zimmertemperatur; am anderen Tage fand ich in dem dieser Rippe entnommenen Mark eine solche Menge von Uebergangszellen mit Kernen in den verschiedenen Austrittsphasen, dass Zellen mit auswanderndem Kern sich häufiger fanden, als Zellen mit einem excentrisch liegenden Kern, und nicht selten konnte man in einem Gesichtsfelde (Syst. 8, 0cul. 3) ihrer 5 und sogar mehr zählen. Es fällt nicht schwer, die Ursache dieser Erscheinung ausfindig zu machen. Das gefärbte Protoplasma, in dem der Kern liegt, beginnt einige Zeit nach dem Tode des Thieres sich zu verdichten und geht in die Leichenstarre über. Dadurch, dass es sich verdichtet, übt es einen Druck auf den Kern aus. Sogar bei der Lage in der Mitte der Zelle kann er in die excentrische weggedrückt werden, wie man dies an den rothen Blutkörperchen von Fröschen beobachtet; da er aber gewöhnlich excentrisch liegt und nun dem erhöhten Druck seitens des erstarrenden Protoplasma ausgesetzt ist, so ist einleuchtend, dass der Kern sich nach der Richtung hin bewegen wird, wo er am wenigsten Widerstand findet, d. h. nach der nächstgelegenen Peripherie hin. Seine Lage wird stetig eine mehr excentrische, sie wird nachher peripherisch, und schliesslich wird der Kern ganz aus der Zelle herausgedrückt und bleibt mit letzterer in einem, oft optisch nicht bemerkbaren Zusammenhange.

Trennt sich der Kern vollkommen von der Zelle? Rind fleisch war nicht im Stande, den Trennungsprozess selbst zu beobachten, obgleich er zu dessen Hervorrufung die verschiedenartigsten Mittel in Anwendung brachte; auch ich habe ihn nicht gesehen. Dafür sah ich aber, wie der Kern bei Dichtigkeitsabnahme des Protoplasma (Picrocarminwirkung) in die Zelle zurückwanderte. Aus dieser Beobachtung ergiebt sich von selbst die Annahme, dass der Kern auch in der Leiche, nach Aufhören der Leichenstarre im Protoplasma, in dasselbe von Neuem zurückkehrt, obgleich wir 
theoretische Einwendungen gegen die Möglichkeit einer vollständigen Trennung des Kernes vom Protoplasma nicht vorzubringen haben.

Der Kernaustrittsprozess wird bei Embryonen weit später beobachtet, als an erwachsenen Thieren. Beim Embryo eines Meerschweinchens beobachtete ich Uebergangszellen mit deutlich austretendem Kern erst nach Ablauf von 72 Stunden nach dem Tode.

Rindfleisch sah diesen Prozess als einen physiologischen an und wollte dadurch die Bildung der rothen Blutkörperchen erklären. Seiner Anschauung nach erreichen die Kerne die Peripherie zum Theil durch amöboide Bewegungen, und nachdem sie die Zelle verlassen, hinterlassen sie in derselben Spuren ihres Verweilens in Form eines Eindruckes, wodurch das Protoplasma die Mützenform bekommt. Letztere Form hat wiederum nach Rindfleisch mehr als jede andere die Fähigkeit, während der Circulation sich in biconcave Scheiben umzuwandeln. Wir wissen jedoch, dass die Mützenform auch im Blute angetroffen wird, und dass sie als Uebergangsform von Scheiben zu Kugeln anzusehen ist, ohne in irgend welcher Beziehung zum Auswanderungsprozess des Kernes zu stehen.

Werden im Knochenmark kernhaltige rothe Zellen häufig angetroffen? Am gesunden Thiere finden sie sich stets mehr oder weniger reichlich. Sogar in Menschenleichen kann man sie so oft antreffen, dass 0 rth und Litten $\left({ }^{19} \mathrm{~S} .745\right)$ sie unter 100 Fällen nur 8 Mal nicht fanden. Auch ich muss diesen Autoren vollkommen beistimmen, wenn sie ihr Verwundern daruber aussprechen, dass es Ranvier "nicht gelungen, im Knochenmark Elemente zu finden, welche das Uebergangsstadium von den Leucocyten zu den rothen Blutkörperchen darstellten " ( ${ }^{12}$ S. 511).

Die Analyse der blassen Zellen ist mit der Analyse der vorhergehenden Gruppen, namentlich der kernhaltigen rothen Zellen mit nicht scharf ausgesprochener Hämoglobinfärbung des Protoplasma, fast vollkommen erschöpft. Mit diesen erfahren sie gleiche Veränderungen, namentlich binsichtlich der Kernbildung nach dem radiären und concentrischen Bildungsmodus. Auf Grund dessen müssen wir auch bei ihnen annehmen, dass die Kernsubstanz während des Lebens diffus im Protoplasma verbreitet ist, und dass die Bildung des Kernes als Leichenerscheinung anzusehen ist.

Bei Sehilderung unserer Beobachtungen saben wir, dass die gewöhnlichen Markzellen einige Eigenthümlichkeiten haben, durch 
welche sie sich recht scharf von den vorhergehenden Gruppen unterscheiden. Vor Allem beobachten wir hier nie eine Kernbildung, wie in den blassen und Uebergangzellen, sondern wir treffen den Kern stets in ausgebildeter Gestalt an. Freilich sehen wir ihn auch hier nicht sogleich nach Anfertigung des Präparates aus vollkommen frischem Knochenmark, doch sehen wir sogleich eine nicht gleiche Lichtbrechung in den einzelnen Zellenabtheilungen, und da wir nun wissen, dass aus der blassen, mehr oder weniger central gelegenen Substanz nach einiger Zeit der Kern sich morphologisch differenzirt, aus der dunkleren peripherischen Substanz sich Zellenkörper bilden, so ist auch der Schluss gestattet, dass der Kern sich hier nicht in Form einer gleichmässig in der ganzen Zelle ergossenen Substanz vorfindet, sondern in Gestalt eines Körpers, welcher schon während des Lebens eine gewisse bestimmte Gegend und Form einnimmt. Wir sehen sofort nach Anfertigung des Präparates die Peripherie an diesen Zellen dunkler und glänzender als den centralen Theil, und müssen daraus schliessen, dass diese dunkle Substanz ein grösseres Lichtbrechungsvermögen besitzt, als die Kernsubstanz, und dass nur darin die Ursache zu suchen ist, warum wir in diesen Zellen den Kern nicht sofort nach Anfertigung des frischen Präparates sehen können. Am Kern haben wir ebenfalls einige Eigenthümlichkeiten beobachtet: er besitzt einen verdickten Contour und letzterer erscheint dadurch doppelt, wir fanden in demselben die Kernkörperchen und schliesslich eine nur geringe oder gar keine Fähigkeit, im Leichenzustande der Zelle einen kleineren Umfang anzunehmen.

Es finden sich jedoch unter ibnen auch solche, in welchen die Körner sehr schwach entwickelt sind und welche einen grossen Kern ohne Verdickung der Contouren und mit kaum bemerkbaren Kernkörperchen besitzen. Der Kern besitzt nicht selten einen Eindruck, welcher in einzelnen Zellen an eine hernienartige Einstälpung des Protoplasma in den Kern erinnert, während letzterer Hufeisenform einnimmt. Schliesslich nimmt der Kern die verschiedensten Gestaltungen an, kann in mehreren Exemplaren vorkommen u. s. w.; sobald das Protoplasma jedoch mehr körnig wird, wird die Gestalt des Kernes regelmässiger, rund oder oval, und immer kommt er dann einzeln vor.

In den Zellen mit weniger entwickelter Körnchenbildung sahen 
wir bereits eine grössere Befähigung $z u$ amöboiden Bewegungen, welche bereits von Bizzozero ${ }^{5}$ in den Markzellen entdeckt wurde*). Ferner constatirten wir in den Zellen mit grösseren Körnern eine starke Neigung zur Haufenbildung, wobei die Grenzen zwischen den Zellen bisweilen so sehr verwischt werden, dass das gauze Bild an eine Körnermasse erinnert, in welcher zerstreut Kerne liegen.

Die Myeloplaxen wurden mit zweierlei typischem Aussehen beobachtet: als grosse körnige Zellen mit zerstreuten Kernen und nicht selten undeutlichen verschwommenen Contouren, oder als Bildungen mit hyalinem oder feinkörnigem Protoplasma und sprossendem Kern. Ausserdem fanden wir Myeloplaxen, in denen nach Zusatz von Essigsäure die Grenzen der Zellen deutlich werden, ferner Myeloplaxen, in welchen durch letzteres Reagens nur einzelne Kerne in der Zelle sichtbar werden, deren Zahl jedoch im Verhältniss zur Grösse der Zelle eine gar zu minime ist, und schliesslicb Körnerschollen, in denen durch Essigsäure keine Kerne entdeckt werden.

Jetzt können wir, auf Grund der vorausgehenden Analyse, einen näheren morphologischen Zusammenhang aller Elemente des Knochenmarkes ausfindig machen und nächstdem ein allgemeines System inrer Histogenese aufstellen.

Der Zusammenhang zwisehen den rothen Blutkörperchen und den kerubaltigen rothen Zellen kann jetzt schwerlich in Zweifel gezogen werden. Die Beobachtungen über die Bildung der gleichmässigen Körnigkeit in den unreifen rothen Blutkörperchen gleichen, indem sie uns einen unanfechtbaren Beweis dafür liefern, dass die Kernsubstanz der Uebergangsformen in den Zellen gleichmässig ergossen ist, zugleich die Kluft aus, welche bisher zwischen den Uebergangsformen und den rothen Blutkörperchen im Mark gesunder Thiere bestand. Bei unseren Beobachtungen wurde bereits erwähnt, dass die Zahl der gleichen Körnchen in den einzelnen Blutkörperchen eine ganz verschiedene ist: in einigen Fällen füllen die Körnchen

*) Besitzen die Uebergangszellen die Fähigkeit, amöboide Bewegungen auszuführes? Ich habe zwei Mal schwache Bewegungen beobachtet; heide Mal aber war das Mark der Leiche so eben gestorbener Thiere entnommen. Im Mark von gesunden Thieren babe ich in den Uebergangsformen keine Bewegungen beobachten können. 
gleichsam das ganze Körperchen, in anderen Fällen finden wir nur 2-3 Körnchen. Diese Verschiedenheit bedeutet eine allmähliche Verminderung der Kernsubstanz in den unreifen Blutkörperchen bis zu ihrem vollkommenen Verschwinden in den gewöhnlichen rothen Blutkörperchen.

Körnigkeit in den rothen Blutkörperchen wurde zuerst von $\operatorname{Erb}^{18}$ constatirt und zwar bei Zuständen des Organismus, welche eine gesteigerte Blutbereitung fordern. Erb benutzte hierzu sehwache Essigsäurelösungen. Diese Beobachtung bat im vorigen Jahre durch Arndt ${ }^{16}$ ibre Bestätigung gefunden. Letzterer fand, dass man im Blute eines jeden Säugethieres unter gewöhnlichen Verhältnissen durch wässerige Lösung von Methylviolett Blutkörpercben mit Körnchen entdecken kann. Arndt's Beobachtung kann ich vollkommen bestätigen, muss jedoch bemerken, dass die Zahl solcher Blutkörperchen im Blute des Menschen, des Hundes und Kaninchens im gesunden Zustande sehr unbedeutend ist. Ferner ist die Körnigkeit solcher Blutkörperchen höchst schwach entwickelt; in der Regel trifft man 2-3 Körnchen an, selten mehr. Die gleichmässige, das ganze Blutkörperchen ausfüllende Körnigkeit, welche wir bei den rothen Blutkörperchen des Knochenmarkes kennen lernten, sieht man bier nicht. Ein vortreffliches Object zum Studium unreifer Blutkörperchen habe ich jedoch im Blute neugeborner Ferkel gefunden, welches gewöhnlich eine Menge derartiger Elemente enthält. Das sich rasch bildende Fibrinnetz fixirt sie oft, und man kann dann mit Bequemlichkeit ihre Veränderungen, unter Einwirkung von verschieden starken Strömen einer Methylviolettlösung, verfolgen, desgleichen Bildung und Dislocation der Körnchen im Blutkörperchen beobachten u. s. w. Wir erbalten freilich bei diesen Beohachtungen vollkommen dieselben Resultate, wie bei den Blulkörperchen des Knochenmarkes, doch um sie bei den letzteren zu erreichen, bedarf' es grösserer Vorsichtsmaassregeln beim Färben, als im Ferkelblut*).

*) Die Untersuchung des Blutes neugeborner Ferkel ist in vieler Beziehung von Interesse. Zunächst ist es mir trotz vieler Versuche nie gelungen, die Blutkörperchen in möglichst unveränderter Gestalt zu erhalten; stets waren sie zusammengeschrumpft. Die Z immermann'schen Elementarkörperchen finden sich hier in einer solchen Unzahl, dass sie gewaltige Haufen bilden. Die Gestalt der rothen Blutkörperchen ist eine sehr variable und bisweilen bizarre, bisweilen mit einem oder zwej regelmàssigen oder unregelmässigen Auswüchsen, 
Der Zusammenhang der Uebergangsformen mit den blassen Zellen unterliegt nach unseren Beobachtungen ebenfalls keinem Zweifel. Nach den geschilderten Beobachtungen ist es uns bekannt, dass viele blassen Zellen bis zur Kernbildung so schwache Spuren von Färbung zeigen, dass man nicht entscheiden kann, ob sie zu den Uebergangsformen zu rechnen sind; erst nach der Kernbildung ist es leichter, sich über die Intensität der Hämoglobinfärbung ein Urtheil zu bilden, obgleich auch dann nicht selten die Farbennüancen so wenig ausgesprocben sind, dass man nicht sagen kann, ob das Protoplasma im gegebenen Falle gefärbt ist oder nicht. Abgesehen von dem allmählichen Uebergang der vollkommen blassen Zellen in gefärbte spricht für den Zusammenhang dieser Formen sowohl die Intensität ihres vitalen Zustandes mit Ausnahme der Färbung, als auch die der Leichenveränderungen. Schliesslich treten die einen wie die anderen in verschiedenen Grössen auf und unter beiden findet man die 8-Form. Auf diesen Zusammenhang ist bereits von Orth und Litten ${ }^{19}$, Osler ${ }^{21}$ und Anderen hingewiesen.

Nachdem wir somit die Stellung der Uehergangsformen zwischen den blassen und den rothen Blutkörperchen festgestellt baben, sei es uns gestattet, die Terminologie der Uebergangszellen kurz zu berühren. Es ist einleuchtend, dass die gefärbte Zelle nichts anderes ist, als eine blasse Zelle, die jedoch die Hämoglobinfärbung angenommen hat, und dass sie hernach in's rothe Blutkörperchen übergeht. Mit Rücksicht auf diese Stellung könnten wir auch bei ihrer Benennung ihre Verwandtschaft entweder zu den blassen Zellen oder zu den rothen Blutkörperchen ausdrücken. Im ersteren Falle könnte man sie, entsprechend den Principien der Virchow'schen Terminologie, Hämoleucocyten, im zweiten Hämatoblasten nennen. Letztere Benennung bat bereits das Bürgerrecht erlangt und wird gewiss für die gefärbten Zellen des Knochenmarks angenommen

welche sich oft umbiegen und gleichsam amöboide (?) Bewegungen ausführen; desgleichen findet man oft kleine Blutkörperchen mit einem langen und dünnen Auswuchs, welcher Bewegungen, ähnlich denen am Samenkörperchen, ausführt. Kernhaltige rothe Zellen werden ebenfalls nicht selten angetroffen. Es ist mir nieht bekannt, ob das Blut eines erwachsenen Schweines ein gleiches Bild liefert. Ich habe nicht gefunden, dass das Blut neugeborner Hunde von dem erwachsener sich wesentlich unterscheidet. 
werden. Im Ferneren werde auch ich mich dieser Bezeichnung bedienen, welche auch von Rindfleis ch gebraucht wird, doch bin ich mir bewusst, dass sie noch einige Zeit zu Missverständnissen führen kann, da gegenwärtig unter diesem Namen die allerverschiedensten Dinge verstanden werden (die Hämatoblasten von Wyssozky ${ }^{25}$, von Hayem ${ }^{13}$, von Fod̀ und Salvioli ${ }^{26}$ a. A.). Dass die Benennung "kernhaltige rothe Zelle" nur dem Leichenzustande entspricht und für den vitalen Zustand nicht passt, das bedarf, scheint mir, keiner weiteren Beweise.

Kehren wir zur Betrachtung des Zusammenhanges der Markelemente zurück. Den Zusammenhang der blassen Zellen mit den gewöhnlichen Markzellen findet man in den Zellen der letzteren Gruppe mit einem grossen Kern ohne Contourverdickung mit schwach entwickelten Kernkörperchen und feiner, ebenfalls schwach ausgebildeter Körnelung.

Der Zusammenhang der gewöhnlichen Markzellen mit den Myeloplaxen der ersten von uns beschriebenen Form, d. b. der gleichkörnigen mit zerstreuten Kernen, sehen wir in den Myeloplaxen, in welchen durch Zusatz von Essigsäure die Zellengrenzen hervortreten. Auch Ne umann ( ${ }^{1}$ S. 97) erwähnt diese Uebergangsformen der Myeloplaxen. Von den Körnerhaufen ist bei Rindfleisch ( ${ }^{7} \mathrm{~S} .27$ ) die Rede. Als Mittelglied zwischen den letzteren und den Myeloplaxen mit glejchmässig zerstreuten Kernen haben wir die Körnerhaufen mit einigen Kernen, welche nur mittelst Essigsäure deutlich werden.

Wir haben folglich eine ganze Reihe von Zellen, welche unter einander im engsten morphologischen Zusammenhang stehen; an einem Ende dieser Reihe stehen die rothen Blutkörperchen, am anderen die Körnerhaufen. Da wir nun den morphologischen Uebergang der einen Form in die andere beobachten können, so schliessen wir auch auf eine genetische Verwandtschaft dieser Elemente. Wir haben nur unter allen Elementen des Knochenmarkes die Anfangsform ausfindig zu machen, aus der man genetisch alle übrigen Formen herleiten kann. Eine solche Anfangsform kann vor Allem eines der äussersten Elemente der von uns aufgestellten Reihe bilden, während das andere Endglied das Schlusselement darstellen wird.

Für die rothen Blutkörperchen ist diese Möglichkeit nicht vor- 
handen. Es ist bekannt, dass sie sich nicht selbständig vermehren können und andererseits, dass sie zu keinerlei productiver morphologischer Metamorphose befähigt sind; schliesslich ist es uns bekannt, dass sie selbst aus Hämatoblasten und diese wiederum aus den blassen Zellen entstehen. Versuchen wir die Histogenese der Markelemente aus Körnerhaufen herzuleiten, so hat auch dieses Element keine Eigenthümlichkeiten eines primären, der Entwickelung fähigen Gebildes; sie selbst, ihrer unregelmässigen Gestalt und ihren verschwowmenen Contouren gemäss, sind eher Myeloplaxen ähnlich, welche ibre Kerne verloren haben und im Zerfall sich befinden. Sehen wir hiernach, ob man die allgemeine Histogenese der Markelemente nicht von den Myeloplaxen beginnen, d. h. annehmen kann, dass die Myeloplaxen zum Zerfall in einzelne Zellen befähigt sind, und dass die Form von Myeloplaxen, in welchen man Zellengrenzen bemerkt, den Anfang der Zellenbildung vorstellt. Wenn wir aber mit Ne a mann ( ${ }^{1}$ S. 98) eine solche Möglichkeit zugeben, so haben wir die Bildungweise der Myeloplaxen ausfindig zu machen. Sie aus den Körnerhaufen herzuleiten, ist unmöglich. Es fragt sich nun, ob sie nicht aus den gewöhnlichen Markzellen sich entwickeln können, indem die Kerne derselben wuchern und die Zelle an Umfang zunimmt.

Es ist uns jedoch bekannt, dass die Kerne der Myeloplaxen ideutisch sind mit denen der körnigen Markzellen, welche stets einen einzelnen Kern besitzen. Zellen mit 2-3 Kernen, welche verdickte Contouren und $3-4$ Kernkörperchen aufzuweisen haben, und welche wir als Uebergangsformen von einer Zellengruppe zur anderen ansehen könnten, finden sich hier nicht; wir müssten sie aber stets antreffen, sobald im Mark Myeloplaxen vorhanden sind, und um so mehr, je mehr Myeloplaxen sich finden. Ihre Entstehungsweise können wir somit nicht ausfindig machen. Doch selbst vorausgesetzt, dass die Myeloplaxen in die Markzellen zerfallen, darf man nicht vergessen, dass ihnen die Zellen mit einem einzelnen Kern und starker Körnelung am nächsten stehen. Geht man somit von den Myeloplaxen aus, so würde die progressive Entwickelung der Elemente ihren Ursprung von den Zellen mit der allergrössten Körnelung nehmen und Formen erreichen, bei denen diese Körnelung gar nicht vorhanden ist, wie z. B. an den blassen Zellen; dieses alles steht jedoch im Widerspruch mit unseren An- 
schauungen über die Morphologie der Zellen in den verschiedenen Phasen ihrer physiologischen Entwickelung.

Doch fassen wir die Sache anders auf. Nehmen wir an, dass nicht die Myeloplaxen die Ausgangsform der Markzellen bilden, indem sie in einzelne Zellen zerfallen, sondern dass die Myeloplaxeu aus Markzellen durch Zusammenfluss der einzelnen Zellen in einen grösseren Körper entstehen. Zu dieser Anschauung sind wir um so mehr berechtigt, da wir in den körnigen Markzellen die scharf ausgesprochene Fähigkeit constatirten, zu Haufen zusammenfliessen und dabei ihre Grenzen zu verlieren. Von diesem Gesichtspunkte aus wird ohne Schwierigkeit die Histogenese der verschiedenen Formen der Myeloplaxen verständlich. Die körnigen Markzellen fliessen nach Beendigung des Cyclus ihrer pbysiologischen functionen in einen grösseren Haufen zusammen, verlieren dabei allmählich ihre Grenzen und Kerne, und verwandeln sich endlich in Körnerbaufen, welche zerfallen.

Es bleiben jetzt zwei Zellenformen übrig, bei denen wir die Ausgangsformen für die Bildung aller Elemente des Knochenmarkes zu suchen haben, dies sind die blassen und die gewöhnlichen Markzellen. Die einen wie die anderen haben die verschiedenste Grösse; in der Grössenverschiedenheit können wir den Ausdruck für das Wachsthum der Zelle sehen. Wir haben jedoch früher constatirt, dass diese zwei Zellenformen nicht gleich oft in verschiedenem Alter angetroffen werden, wenn wir letzteres nur annähernd nach der Grösse bemessen wollen. Wir haben namentlich gefunden, dass je kleiner die farblose Zelle ist, um so häufiger sie zur Kategorie der blassen, und umgekehrt, je grösser sie ist, um so häufiger sie zur Kategorie der gewöhnlichen Markzellen gehört, und dass die kleinsten morphologischen Bildungen des Knochenmarkes ausnahmslos zu den blassen Zellen gehören. Schon aus dieser Combination kann man annehmen, dass den Ausgangspunkt eher die blassen, als die gewöhnlichen Markzellen bilden können. Ferner ist uns bekannt, dass man die Markzellen nicht in der Theilungsperiode antrifft. Der Einwand von Neumann ( ${ }^{1}$ S. 94), dass die Form der Markzelle zufolge ihrer Contractilität sofort nach Entnahme des Markes aus der Knochenhöhle oder nach dem Tode des Thieres eine kuglige Form annehmen muss, wird durch den Umstand entkräftet, dass die Hämatoblasten und blassen Zellen ihre 8-Form 
lange bewahren, so dass man sie nicht selten selbst 24 Stunden nach dem Tode des Thieres beobachten kann. Andererseits sieht man nicht selten Eindrücke am Kern der Markzellen und bemerkt gewöhnlich nicht eine entsprechende Vertiefung am äusseren Zellencontour. Wir können nur constatiren, dass der Kern in den Markzellen mit nicht so ausgesprochener Körnelung seine Gestalt und seine Lage in der Zelle ändern, sich theilen kann u. s. w., aber das Vorhandensein von 2-3 Kernen in der Markzelle spricht ebensowenig für ihre Tendenz zur Theilung, wie eine noch grössere Anzahl derselben in den weissen Blutkörperchen zu der Annahme berechtigt, dass z. B. ein Blutkörperchen mit 5 Kernen sich nachher in 5 Theile theilen, $d . h$. fünf Tochterzellen hervorbringen wird.

Wir sind somit bei unserer histogenetischen Analyse zu den blassen Zellen als den Anfangsformen der Elemente des Knochenmarkes angelangt, sei es nun, dass wir von den rothen Blutkörperchen, sei es, dass wir von den Körnerschollen, d. b. den beiden äussersten Repräsentanten der von uns aufgestellten Elementenreihe, ausgehen. Sehen wir nun zu, in wie weit die blassen Zellen ihrer Bestimmung, gleichsam als Material für die Bildung sowobl der Markzellen als auch der Hämatoblasten zu dienen, entsprechen können. Die blassen Zellen finden sich von der verschiedensten Grösse und dazu nicht selten in der Theilungsperiode. Wir können hier folglich einen Wachsthums- und Vermehrungsprozess annehmen. Durch Wachsthum können die kleinen Zellen einen grossen Umfang erlangen und dabei in die eine oder andere Zellenform übergehen; durcb Theilung können sie allmählich ihr kleinstes Volumen einnehmen und von Neuem ihren Entwickelungscyclus beginnen. In einem solchen Kreislauf fänden wir eine hinreichende Quelle nicht nur für eine fortwährende Selbsterzeugung, sondern auch für den Uebergang in andere Markelemente, wenn wir bei dieser Entstehungsweise nicht auf mehrere unüberwindliche Schwierigkeiten stiessen. Es wurde bereits öfter erwähnt, dass das quantitative Verhältniss zwischen Kernsubstanz und Protoplasma in den blassen Zellen und den Hämatoblasten von verschiedener Grösse ein umgekehrtes ist: in den kleinen Zellen findet sich viel Kernsubstanz and wenig Protoplasma, in den grossen viel Protoplasma und relativ wenig Kernsubstanz. Ferner sahen wir, wenn man die Grösse des Kernes im glänzenden homogenen Zustande (also in seinem Leichenzustande) in den kleinen blassen 
und Uebergangszellen mit kaum bemerkbarer Protoplasmasichel vergleicht mit der Grösse des Kernes in den grossen Zellen, wo der Kern einen geringen Theil ihrer Grösse ausmacht, dass sich dabei ergiebt, dass die Grösse der Kerne in diesen Zellen, wenn überhaupt, so nur in einem höchst geringen Grade von einander verschieden ist. Das Zellenwachsthum müsseu wir folglich hauptsächlich auf Rechnung der Zunahme an Protoplasma setzen, die Kernsubstanz dagegen nimmt dabei an Umfang hauptsächlich auf Kosten ihrer Dichtigkeit zu, d. h. sie wird durch Eindringen von Protoplasmamolekeln immer mehr verdünnt, und wenn sie überhaupt wächst, so bleibt sie im Wachsthum jedenfalls hinter dem Protoplasma sehr weit zurück. Wir wissen ferner, dass nur die mehr entwickelten Individuen der blassen Zellen den Theilungsprozess eingehen; bei den Zellen kleinen Kalibers, in denen die Kernsubstanz dem Protoplasma gegenüber vorherrschend ist, kommt eine Theilung als äusserste Seltenheit vor; bei den allerkleinsten blassen Zellen, in denen man nur schwer das Protoplasma nachweisen kann, wird Theilung überhaupt nicht beobachtet. Von diesen kleinsten, gleichsam nur aus Kernsubstanz bestehenden Elementen ausgehend, können wir einen ganz allmählichen Uebergang zu den allergrössten Zellen durch allmähliche Protoplasmazunahme construiren. In der so aufgestellten Reihenfolge der blassen Zellen verschiedener Grösse müssen wir das kleinste Element als Ausgangselement für die blassen Zellen aller Grössen, folglich auch für alle übrigen Bildungen des Markes hinstellen, und wollen das kleinste, protoplasmalose Element Protoleucoeyt nennen. Wir können jedoch die Protoleucocyten selbst nicht durch Theilung der entwickelteren Individuen dieser Zellengruppe entstehen lassen. Jede sich theilende Zelle erzeugt eine Nachkommenschaft, welche nur das Leben der Mutter fortzusetzen im Stande ist. Standen vor der Theilung Kernsubstanz und Protoplasma in einem bestimmten Verbältniss zu einander, so werden durch Theilung Tochterzellen mit annähernd demselben Verhältniss beider Substanzen $\mathrm{zu}$ einander erstehen. Da aber nur die entwickelten Individuen, in welchen die Protoplasmamenge vor der Kernsubstanz vorherrschend ist, den Theilungsprozess eingehen, so wird auch in den Tochterzellen dieses Ueberwiegen des Protoplasma in demselben Grade wie bei der Matterzelle zum Ausdruck kommen. Die Tochterzellen können folglich ihre Existenz 
nur mit der Epoche und dem Alter beginnen, welches die Mutterzelle im Cyelus ihrer vitalen physiologisehen Umwandlungen erreicht hatte, sie können aber keine junge Generation, welche bauptsächlich aus Rernsubstanz besteht, vorstellen.

Hält man es aber für unmöglich, Protoleucocyten aus den ausgebildeten Individuen durch Theilung entstehen zu lassen, und zweifelt man an der Möglichkeit, dass sie selbst durch Theilung entstehen können, so ist die Frage nach ihrer Entstehungsweise eine nur noch dringendere geworden, ohne dass wir eine bestimmte Antwort zur Hand hätten. Ich habe im normalen Knochenmark mit Bestimmtheit keine Bildungen beobachten können, welche als Grundlage zur Entwickelung von Protoleucocyten dienen könnten, ähnlich den von Neumann ( ${ }^{2}$ S. 469$)$ beschriebenen Zellen mit Einschliessungen, und habe nicht gesehen, dass sie in den Markzellen sich bildeten, wie die Hämatoblasten Hayem's, seiner Anzabe nach, in den weissen Blutkörperchen sich entwickeln sollen ${ }^{14}$.

Jetzt haben wir die Bedeutung des Theilungsprozesses in den Hämatoblasten und blassen Zellen genauer festzustellen. Die ausschliesslich productive Bedeutung dieses Prozesses wurde bereits durch die Erkenntniss erschüttert, dass hierdurch dennoch keine jüngere Generation derselben Zellen zu Stande kommen kann. Wenn wir andererseits auch nicht wissen, wie die Protoleucocyten entstehen, so ist doch bekannt, dass sie stets in solchem Ueberfluss auftreten, dass hier allein eine vollkommen hinreichende Quelle für die Bildung aller Markelemente gefunden werden könnte. Wir haben gesehen, dass hauptsächlich die Hämatoblasten grossen Kalibers sich theilen und dabei Tochterzellen von $6-7 \mu$ entstehen, welche ihrer Grösse nach den rothen Blutkörperchen sich nähern. Hiermit eröffnet sich uns eine neue Seite der Hämatoblastentheilung, nehmlich. die Regulirung der Grösse der rothen Blutkörperchen.

Die Bedeutung der Hämatoblastentheilung als eines nicht nur productiven, sondern auch die Grösse der rothen Blutkörperchen regulirenden Prozesses ist bereits von Rindfleisch zugegeben. Seiner Anschauung nach betragen die Tochterzellen an Grösse jedoch nicht die Hälfte ( $\left.{ }^{7} \mathrm{~S} .26\right)$, sondern $\frac{2}{5}$ der Mutterzelle, etwas, das, zum wenigsten vom eigenen Standpunkte Rindfleisch's aus, ganz unerklärlich erscheint. Andere Autoren (Kölliker, Erb, Neumann u. A.) sehen eine allmähliche Volumabnahme der Kerne in den 
Hämatoblasten als einen für den Uebergang in rothe Blutkörperchen nothwendigen Prozess an, und damit könnte man annehmen, dass das rothe Blutkörperchen entsprechend dem Hämatoblasten bis auf die Grösse des Kernes an Grösse abnehmen muss; doch da Rindfleisch diese allmähliche Grössenabnahme des Kernes in Abrede stellt, so wird eine solche Grössenabnahme der Tochterhämatoblasten bei der Theilung geradezu unverständlich, und überdies entspricht sie nicht den Thatsachen.

Ebensowenig kann ich die Beobachtung von Erb ( $\left.{ }^{18} \mathrm{~S} .173\right)$ bestätigen, dass die unreifen Blutkörperchen (seine „Uebergangsformen") durch ihre Grösse auffallen sollen, da letztere die der reifen rothen Blutkörperchen um $\frac{1}{4}$, ja sogar um $\frac{1}{3}$ übertreffen sollen. Am besten kann man sich von dem Gegentheil dieser Beobachtung überzeugen, wenn man das Blut eines neugeborenen Ferkels untersucht. Hier werden die Körner nach Wirkung von Methylviolettlösung in den Blutkörperchen aller Grössen angetroffen, auch diejenigen nicht ausgeschlossen, welche ihren Dimensionen nach als Mikrocyten bezeichnet werden müssen.

Das Schema für den allgemeinen morphologischen Entwickelungsprozess der Elemente des Knochenmarkes kann somit folgendermaassen aufgestellt werden:

Die Protoleucocyten sind die Ursprungselemente für alle Bildungen des Knochenmarkes. Sie entwickeln sich, d. h. sie wachsen im Umfange auf Kosten der Grössenzunahme des Protoplasma. Dabei können auf allen Entwickelungsstufen die blassen Zellen sich in Hämatoblasten umwandeln, dadurch dass ihr Protoplasma Blutfarbstoff aufnimmt. Die Hämatoblasten färben sich allmählich intensiver und erreichen durch Wachsthum und durch Theilung die Grösse der rothen Blutkörperchen, machen das Stadium der unreifen Blutkörperchen durch und gehen schliesslich (vollkommen) in die gewöhnlichen rothen Blutkörperchen über, welche keine Kernsubstanz enthalten. Erfolgte jedoch keine Färbung der blassen Zellen, was aller Wahrscheinlichkeit nach von verschiedenen Bedürfnissen des Organismus abhängt, so beginnt die blasse Zelle degenerative Prozesse durchzumachen. Ihr Protoplasma geht dabei derartige Umwandlungen ein, dass es im Leichenzustande eine mehr oder weniger ausgesprochene Körnigkeit zeigt; schliesslich kann es auch während des Lebens körnig erscheinen. Die Kernsubstanz, welche die ganze 
blasse Zelle eingenommen hatte, beginnt in ein besonderes morphologisches Organ sich $\mathrm{zu}$ differenziren, welches anfangs beweglich und seinem Aussehen nach veränderlich ist, darnach aber ällmählich zu einer bestimmten runden oder ovalen Form "gerinnt". Nachdem die Zellengruppe eine bestimmte Degenerationsstufe erreicht hat, büsst sie ihre Grenzen ein und geht in Myeloplaxen über; letztere wiederum verlieren ihre Kerne und gehen allmählich in Körnerschollen über, welche zerfallen.

Nach Beendigung der Analyse müssen wir auf einige Betrachtungen anlässlich der von uns gefundenen Thatsachen eingehen.

Vor Allem haben wir gefunden, dass der Kern als morphologischer Bestandtheil der Zelle in den Hämatoblasten und blassen Zellen eine Leichenerscheinung ist. Diese Ansicht, dass der Kern als postmortale Bildung auftritt, wurde bereits im Jahre 1853 von Moleschott ${ }^{29}$ mit Bezug auf die rothen Blutkörperchen des Frosches ausgesprochen, und er ist der einzige Autor, mit dem meine Beobachtungen in dieser Beziehung vollkommen übereinstimmen*). In neuester Zeit hat sich Golubew in gleicher Weise ausgesprochen. Auf Grund seiner Untersuchungen über den Einfluss des Inductionsstromes auf die weissen Blutkörperchen des

*) Da der Beobachtungen Moleschott's ond seiner auf dieselben sich stützenden Anschauungen, so weit mir bekannt, in der neuen Literatur nicht Erwähnung geschieht, so will tch mir erlauben, die wenigen hierauf bezüglichen Zeilen wörtlich anzuführen. Nachdem er constatirt hat, dass in den rothen Blutkörperchen des Frosches während des Lebens kein Kern sich findet, und dass letzterer ein Gerinnungsproduct vorstellt, beschreibt Moleschott den Kernbildungsprozess folgendermaassen: „Anfangs zejgt sich die Gerinnung in der Form eines runden Schattens, der erst dicht an dem Umkreis der Zelle liegt, sich aber nach und nach zusammenzieht, wie der Kuchen des aus der Ader geflossenen Blutes. So entstehen nach und nach ovale und runde Kerne, die mit dem ursprünglichen Bau der Zelle nichts gemein haben “ (S. 82). Arnd t ${ }^{16}$ spricht auch davon, dass es keinen Kern als präexistirendes Organ in diesen Elementen giebt, dass er vielmehr in Folge tiefer Ernährungsstörungen der Zelle zu Stande kommt, aber er spricht nicht von deutlichen und namentlich breiten Contouren des Kernes und seiner allmählichen Umfangsabnahme. Er beschreibt nur das Zellencentrum und die in diesem vor sich gehenden Veränderungen, was ihn veranlasst anzunehmen, dass das Protoplasma selbst, welches im Centrum des Blutkörperchens liegt, in so kurzer Zeit durch Dichtigkeitszunahme so auflälige Modificationen erleidet. 
Frosches ${ }^{34}$, so wie auf die spindelförmigen Elemente der Capillaren desselben Thieres ${ }^{33}$, spricht er sich zu Gunsten der Kernbildung als Leichenerscheinung aus, nicht nur in den genannten Elementen, sondern auch in allen Zellen des Organismus, in welchen wir den Kern nicht sofort nach Entfernung der Zelle aus dem lebenden Organismus sehen ${ }^{35}$. Nächstdem negirt Stricker ${ }^{3 x}$ auf Grund seiner Beobachtungen über die Kernentstehung in den weissen Blutkörperchen des Frosches ebenfalls das Vorhandensein des Kernes als eines präexistirenden Organs in den lebenden Zellen, zum wenigsten in einigen Formen derselben. Der Kern ist, seiner Anschauung nach, das Resultat chemischer Prozesse in der Zelle, welche in der Abkapselung des Protoplasma ihren Ausdruck finden; er tritt auf und verschwindet in der Zelle, wie die „Wellen am Wasser".

Ueber die Ursachen, warum man in den erwachsenen Leucocyten die existirenden Kerne im vitalerr Zustande nicht sieht, war bereits bei der Analyse der Morphologie der gewöhnlichen Markzellen die Rede. Hier wollen wir hinzufügen, warum in einzelnen Fällen der Kern auch während des Lebens sichtbar sein kann. Das Protoplasma ist hier die am meisten lichtbrechende Substanz. Der in ihm befindliche Kern kann dieses Lichtbrechungsvermögen im geraden Verhältniss seiner Dicke bei gleicher Dichtigkeit herabsetzen; bei der Kugelform aber verläuft diese Verdickung von der Peripherie aus wie in einem Keil, hier wächst die Dicke, wenn auch nicht rasch, so doch allmählich, was optisch durch allmählichen Uebergang der einen Substanz in die andere seinen Ausdruck findet. Das Bild wird ein ganz anderes werden, wenn in der Zelle statt einer Kugel ein Cubus sich befindet; der die Lichtbrechung herabsetzende Einfluss der Kernsubstanz tritt sofort an den Tag und man wird einen um so schärferen, linearen Contour sehen, je dicker die Kernschicht im Verhältniss zur Protoplasmaschicht ist. Bekannt ist ja die Fähigkeit des Kernes, namentlich bei seinen Bewegungen in der Zelle, die allerverschiedensten Formen anzunehmen, in den verschiedensten Richtungen sich zu verdicken und zu verdünnen und folglich dabei Contouren anzunehmen, welche den linearen ähneln. Die Kerne treten in der That auf und verschwinden dann, wie „Wellen am Wasser", doch dies nicht im chemischen, - wie Stricker glaubt, - sondern nur im optischen Sinne. 
Ferner fanden wir, dass die Kernsubstanz in den blassen Zellen und Hämatoblasten im gleichmässig diffusen Zustande sich befindet und nur nach dem Tode das Bestreben hat, sich zu verdichten, wobei sie nicht selten, wie z. B. bei der radiären Kernbildung ein körniges Aussehen annimmt, darnach Fasern sich bilden, welche allmählich sich contrahiren, und alles mit Bildung eines mehr oder weniger festen Körpers abschliesst. Die Grundursache dieser Erscheinung ist uns nicht bekannt, wir besitzen jedoch in der Blutgerinnung, als Leichenerscheinung, einen analogen Prozess. Wir wissen, dass die Bildung des Kernes und des Fibrinniederschlages nach dem Tode des Thieres zeitlich nahe stehen. Wir wissen ferner, dass diejenigen Stoffe, wie z. B. eine Kochsalzlösung, welche die Blutgerinnung aufhalten, auch die Kernbildung aufhalten; dass in schwachen alkalischen Lösungen das so eben gebildete Fibrin ebenso verschwindet ( $\left.{ }^{11} \mathrm{~S} .101\right)$, wie der Kern in den Hämatoblasten unter Einwirkung einer 1 procentigen Lösung von chromsaurem Ammoniak in Serum, dass das Blat von Embryonen ebenso längere Zeit hindurch nicht gerinnt, wie die Bildung der Kerne in vielen Hämatoblasten lange auf sich warten lässt u. s. w. Doch erstreckt sich diese Analogie beider Prozesse nicht bis zur vollkommenen Identität, die Kernsubstanz ist nicht mit dem Fibrin identisch; unter dem Einfluss von Essigsäure wird das Fibrin verschwommen, blass und verschwindet allmählich, während die Kernsubstanz zusammenschrumpft und ein glänzendes Aussehen annimmt; - von den chemischen Unterschieden nicht zu sprechen ${ }^{22}$.

Im Protoplasma der rothen Blutkörperchen fanden wir ebenfalls eine Leichenverdichtung oder Leichenstarre, eine Erscheinung, welche ohne Zweifel mit den oben beschriebenen und auch den Leichenerscheinungen in den Muskeln eine Analogie besitzt.

In den Myeloplaxen fanden wir eine der Untergangsformen der Markzellen, indem die Kerne allmählich verloren gehen und die Zellen in Körnerschollen sich verwandeln. Einen ähnlichen Prozess hat Weigert ${ }^{36}$ bei einigen pathologisehen Prozessen beobachtet. Auch er beobachtete einen Zusammenfluss der Zellengrenzen, ein Verschwinden der Kerne und dadurch Umwandlung in Körnerschollen, welche er für fibrinös hält und daher mit Cohnheim den ganzen Prozess als Coagulationsnekrose bezeichnet. Die Myeloplaxen mit Rindfleisch ( ${ }^{7}$ S. 27) als eine Ablagerung für überschüssiges 
Bildungsmaterial anzusehen, ist deshalb unstatthaft, weil ich dieselbe oft in relativ grosser Menge im Marke von Phthisikern gefunden habe, wo doch von überschüsšigem Bildungsmaterial schwerlich die Rede sein kann. Man kann sie gleich oft nicht nur in Marktheilen antreffen, welche unmittelbar am Knochen liegen, sondern auch in centralen Theilen, woraus folgt, dass die Ansicht, als lägen sie nur in den Howship'schen Lacunen, durch Beobachtung sich nicht bestätigt. Andererseits können wir ihre Bestimmung nicht in der Resorption der Knochensubstanz finden, denn man findet ganz gleiche Bildungen z. B. in den Gefässen bei Organisation des Thrombus (Senftleben ${ }^{30}$ ), ferner in Tuberkeln, in den Knoten der Perlkrankheit (Kirilow ${ }^{37}$ ) u. s. w. Das Verschwinden der Kerne in den Myeloplaxen ist verständlicherweise nichts Anderes als eine chemische Umwandlung der Kernsubstanz in einen anderen Eiweisskörper, welcher unter Einwirkung von Essigsäure nicht zusammenschrumpft und vielleicht sogar im Blutplasma löslich ist. Die Körnerschollen zerfallen, d. h. ein Theil ihrer Eiweisskörper löst sich auf und geht in die Oeconomie des Organismus über, die übrigen Körner können in's Blut ubertreten und in demselben in Form von „freien“ Körnern circuliren. Die Zimmermann'schen Körper nehmen aller Wabrscheinlichkeit nach ihren Ursprung aus den Körnerschollen. Die mikrochemischen Reactionen beider Bildungen sind identisch (siehe unten Hayem's Hämaloblasten). Ferner spricht für diese Anschauung die Beobachtung 0sler's"1, wo in einem Falle von perniciöser Anämie die Zimmermann'schen Körper aus dem Blute vollkommen verschwunden waren und im Knochenmark desselben Individuums nach dem Tode sich gar keine Myeloplaxen fanden.

Wir können selbstverständlieh nicht entscheiden, in welchem Zusammenhange, - ob in einem mechanischen oder chemischen, - die Kernsubstanz und das Protoplasma in den Hämatoblasten stehen, ebenso wenig können wir auf die Frage antworten, was aus der Kernsubstanz des Hämatoblasten bei dessen Umwandlung in ein gewöhnliches Blutkörperchen wird. Wird sie aus der Zelle ausgeschieden, oder verwandelt sie sich in Protoplasma? Berücksichtigt man die Unbeständigkeit der Eiweisskörper, so hat letztere Annahme ebenso viel Wahrscheinlichkeit für sich als erstere. Uns ist nur bekannt, dass die Kernsubstanz in unreifen Blutkörper- 
chen allmählich sich vermindert bis zum schliesslich vollkommenen Schwunde derselben in den gewöhnlichen rothen Blutkörperchen.

In gleicher Weise kann die Frage, woher das Hämoglobin stammt, auch nicht einmal annähernd beantwortet werden. Nur eines ist zu erwähnen, dass in denjenigen Fallen, wo eine verminderte Blutbereitung stattfindet, was man aus der geringen Anzahl von Hämatoblasten im Mark ersieht, z. B. bei Phthisikern, eine Menge von Pigment angetroffen wird, und dass umgekehrt bei einem gesunden Thiere, mit normaler Blutbereitung, Pigmentzellen äusserst selten sich finden. Man könnte daher glauben, dass die Ausscheidung des Hämoglobins beim Untergange rother Blutkörperchen im Knochenmark unter normalen Bedingungen an seine Aufnahme in die neugebildeten Elemente gebunden ist, dass unter abnormen Umständen jedoch das ausgeschiedene Hämoglobin bleibt in Gestalt von Blutpigment.

Die Behauptung von Flemming $\left({ }^{24} \mathrm{~S} .364\right)$, dass nur indirecte Zellentheilung existirt, findet in meinen Untersuchungen keine Bestätigung. Die typischen 8-Formen von lebenden Hämatoblasten und blassen Zellen enthalten weder eine Kernfigur, noch überhaupt einen Kern als morphologischen Bestandtheil der Zelle.

Es bleibt uns nur noch übrig, jene Versuche zu berücksichtigen, welche den Ort der Bildung rother Blutkörperchen bei erwachsenen Säugethieren nicht im Knochenmark, sondern im Blute selbst finden und als Vorstufen ihrer Entwickelung bier circulirende Bildungen ansehen wollten. Solcher Versuche sind in letzterer Zeit zwei bekannt: der eine gehört Semmer ${ }^{27}$, welcher unter Anleitung von AI. Schmidt arbeitete, der andere Hayem ${ }^{13}$. Hinsichtlich ersterer Arbeit genü̈gt es, zu erwähnen, dass die Grundanschauung des Autors eine Wiederholung der schon längst zurückgewiesenen Moleschott'schen Lehre ist, wonach die rothen Blutkörperchen aus jenen, nicht selten im Blute angetroffenen, weissen Blutkörperchen sich entwickeln sollten, welche eine mehr ausgesprochene Körnelung, einen grösseren Glanz und Spuren von Hämoglobinfärbung zeigen ${ }^{29}$.

Wenden wir uns somit zu Hayem. Seiner Ansicht nach circuliren die Elemente, aus denen die rothen Blutkörperchen bei den Säugethieren sich entwickeln nnd die von ihm als Hämato- 
blasten benannt werden, im Blute selbst: Seiner Beschreibung nach sind dieses kleine, höchst delicate, sehr veränderliche, schwach gefärbte Bildungen, welche, wenn man sie im Blutplasma untersucht, sehr bald farblos werden, stark das Licht brechen und oft eckige Körner werden, welche letzteren sich an der Blutgerinnung dadurch betheiligen, dass ihre Auswüchse mit den Fasern des Fibrinnetzes verlöthen. Beobachtet man sie in Jodserum und in Lösungen neutraler Salze, so erscheinen sie in Form homogener, kernloser Bläschen, mit einer Spur von Färbung. Ihre Substanz unterscheidet sich vom Protoplasma der rothen Blutkörperchen durch ihren grösseren Widerstand gegen Essigsäure und Wasser, aber beide Elemente erscheinen kernlos und homogen, beide gehen in gleicher Weise durch Zusatz von Aetzkali zu Grunde, zeigen ein gleiches Verhalten gegen Eosin und haben eine gleiche Hämoglobinfärbung, obgleich die letztere in den Hämatoblasten rasch schwindet.

Ich habe nach Hayem's Angaben die Blutuntersuchungen bei $-1{ }^{\circ} \mathrm{C}$. angestellt und dennoch keine Spur von Färbung in seinen Hämatoblasten entdecken können. Der Hinweis auf ein gleiches Verhalten des Eosins beiden Elementen gegenüber ist nicht beweisend, da in einer spirituösen Lösung (von Eosin und Alaun, je 1 Theil auf 200 Theile Alkohol) alle Eiweisskörper des frischen Blutes gerinnen und in gleicher Weise sich färben. Die Reaction gegen caustische Alkalien ist ebenfalls wenig überzeugend, denn auf Zusatz einer 33procentigen Aetzkalilösung geht gleich rasch das Protoplasma der rothen Blutkörperchen, wie der Kern in den Hämatoblasten des Knochenmarks zu Grunde. Auf Grund ihrer Reaction gegen Essigsäure und Wasser kann man sie eher dem Kern der weissen Blutkörperchen, als dem Protoplasma der rothen als nahestehend ansehen. Hierüber hat sich Zimmermann $\left({ }^{28} \mathrm{~S} .177\right)$, der zuerst ausführlich diese Bildungen beschrieb, welche seitdem seinen Namen tragen, bereits sehr bestimmt ausgesprochen.

Noch deutlicher tritt ihre Verschiedenheit von den rothen Blutkörperchen hervor, wenn man sie mit den kleinen Blutkörperchen (Microcyten) vergleicht, welche nach Hayem's Ansicht den Ueber* gang von den Zimmermann'schen Körpern zu den gewöhnlichen rothen Blutkörperchen bilden sollen und welche von ihm daher als unreife rothe Blutkörperchen (hématies nains) bezeichnet werden. 
Untersucht man das Blut ohne Reagens, so sieht man, dass die Zimmermann'schen Körper rascher und stärker als alle übrigen Bildungen des Blutes die Tendenz besitzen, sich neben einander zu lagern und Haufen zu bilden, die Mikrocyten dagegen besitzen diese Neigung überhaupt nicht. Kommen die Zimmermann'schen Körper mit dem objectglase in Berührung, so bleiben sie daran fest kleben, und lässt man nun z. B. Kochsalzlösung durch das Präparat strömen, so verbleiben sie am längsten an derselben Stelle am Glase; - die Mikrocyten dagegen bleiben unter allen Bedingungen des Blutes am wenigsten am Glase kleben und mit jeder Strömung im Präparat werden sie ausserordentlich leicht mitgerissen und aus dem Gesichtsfelde fortgetragen. Ueber den Widerstand der Zimmermann'schen Körper gegen Essigsäure und Wasser spricht Hayem selbst, und doch sind es wiederum die Mikrocyten, welche zuerst unter Einwirkung der genannten Reagentien ihre Färbung und ihre Contouren verlieren und gleichsam vollkommen aus dem Gesichtsfelde verschwinden. Endlich verhalten sich beide Elemente vollkommen verschieden gegen eine wässerige Lösung von Methylviolett: die Zimmermann'schen Körper färben sich vollkommen und augenblicklich, gleicb dem Kern und den Körnern der Leucocyten, die Mikrocyten dagegen verlieren rasch ihr Hämoglobin und versehwinden aus dem Gesichtsfelde, ohne sich zu tingiren. Ich glaube, dass die angeführten Vergleiche der beiden Elemente hinreichen, um sich nicht von der Verwandtschaft, sondern vielmehr von dem vollständigen Gegensatz der Eigenschaften dieser beiden, nur ihrer Grösse nach einander einigermassen nahestehenden Bildungen $\mathrm{zu}$ überzeugen.

\section{Die Resultate:}

1. Die Hämatoblasten sind wirklich die Uebergangsformen der blassen Zellen zu rothen Blutkörperchen.

2. Die blassen Zellen sowie die Hämatoblasten enthalten während des Lebens keinen Kern als morphologisehen Bestandtheil der Zelle: die Kernsubstanz befindet sich im Leben gleichmässig durch die ganze Zelle verbreitet.

3. Die Umwandlung der Hämatoblasten in rothe Blutkörperchen geschieht so, dass die Kernsubstanz allmählich sich vermindert bis zum vollständigen Verschwinden. 
4. Die Kernbildung in den Hämatoblasten und blassen Zellen ist eine postmortale Erscheinung, die durch Neigung der Kernsubstanz zu postmortaler Verdichtung bedingt wird.

5. Der Kernbildungsprozess in den beiden Zellenarten ist ein der Blitgerinnung analoger, und die Kernsubstanz, ihren Eigenschaften nach, dem Fibrin verwandt, aber nicht mit ihm identisch.

6. Die Neigung der Kernsubstanz zur postmortalen Verdichtung wird beschränkt durch die Dichtigkeit des Medium (Protoplasma), welches dieselbe verdünnt. Geht die Masse der Kernsubstanz unter ein gewisses Minimum herunter, so fällt sie auch nach dem Tode der Zelle aus ihrem diffusen Zustande nicht aus; werden die Molekeln der Kernsubstanz jedoch durch rasche Verdünnung des Protoplasma mittelst der wässerigen Lösung von Methylviolett aus ihrem Gleichgewichtszustande ausgelöst, so vereinigen sie sich zn kleinen Körnchen, die in eine gemeinsame Masse nicht mehr zusammenfliessen, sondern als vereinzelte Zusammenflusscentren in dem Rayon der Zelle, wo sie sich gebildet hatten, bleiben.

7. In der Leiche erwachsener Säugethiere fängt die Kernsubstanz der Hämatoblasten und blassen Zellen sofort nach dem Tode an, sich zu verdichten. Zu dieser Zeit bewahrt das Protoplasma noch seine vitale Dichtigkeit, welche dem Verdichtungsprozess der Kernsubstanz, wenn dieselbe in hinreichender Masse sich vorfindet, keinen Widerstand darbietet, in Folge dessen in der Leiche der Kern der Hämatoblasten sich gewöhnlich nach dem concentrischen Modus bildet.

8. Das Protoplasma der rothen Blutkörperchen, sowie das der Hämatoblasten und blassen Zellen nimmt ebenfalls nach dem Tode an Dichtigkeit zu oder kommt in eine "postmortale Erstarrung"; die Verdichtung des Protoplasama aber fängt später an, als die der Kernsubstanz.

9. Wenn der Verdichtungsprozess der Kernsubstanz bei der schon eingetretenen postmortalen Verdichtung des Protoplasma beginnt, so bildet sich der Kern nach dem radiären Modus.

10. Die Abweichungen der Kernbildung von den typischen Bildungsweisen, z. B. bei der Verdunstung des Präparates, werden durch die gleichzeitige Verdichtung von zwei ungleichmässig verdichtenden Substanzen bedingt.

11. Die blassen Zellen sind Elemente, welche entweder durch 
Einverleibung von Hämoglobin in Hämatoblasten oder in gewöhnliche Markzellen übergehen.

12. Die gewöhnlichen Markzellen unterscheiden sich von den blassen Zellen dadurch, dass die Kernsubstanz der ersteren schon wäbrend des Lebens eine gewisse morphologische Form bekommt. Das Protoplasma wird immer stärker lichtbrechend und geht allmählich in einen körnigen Zustand über.

13. Die blassen Zellen selbst entwickeln sich durch Wachsthum aus Protoleucocyten, die aus Kernsubstanz bestehen. Der Wachsthumsprozess besteht hauptsächlich in einer allmählichen $\mathrm{Zu}$ nahme des Protoplasma, das die Kernsubstanz mehr und mehr rareficirt.

14. Die Myeloplaxen mit körnigem Protoplasma und in demselben zerstreuten Kernen sind eine der Formen, in der die gewöhnlichen Markzellen zu Grunde geben. Nachdem dieselben einen gewissen Grad der Degeneration erreicht haben, fliessen sie zusammen, verlieren allmählich zuerst ihre Grenze, dann ihre Kerne, und zuletzt wandeln sie sich in körnige Schollen um, welche zerfallen.

15. Der Theilungsprozess der Hämatoblasten muss als ein Prozess, welcher hauptsächlich die Grösse der rothen Blutkörperchen regulirt, aufgefasst werden.

16. Der Austritt des Kernes aus den Hämatoblasten wird durch die postmortale Verdichtung des Protoplasma, welches den excentrisch liegenden Kern herausdrückt, bedingt.

17. Die Versuche, alle Vorstufen der Entwickelung der rothen Blutkörperchen bei den erwachsenen Säugethieren ausser dem Knochenmarke und zwar im Blute selbst zu finden, haben keine feste Stiutze.

Diese Arbeit entstand im Breslauer pathologischen und Petersburger histologischen Institut. Den Directoren beider Institute, den Herren Professoren Ponfick und Sawarykin, fühle ich mich zu Dank verpflichtet für die Mittel, welche mir von denselben zu meinen Arbeiten gewährt wurden. Ich kann ferner nicht umbin, meiner aufrichtigen Verbindlichkeit dem I. Assistenten des Breslauer pathologischen Instituts, Herrn Dr. Marchand, gegenüber Ausdruck zu geben für seine stete Bereitwilligkeit, dem Anfänger namentlich in der experimentellen Technik behülflich zu sein. 


\section{L i t e r a t u r.}

1. E. Neumann, Ueber die Bedeutung des Knochenmarkes für die Blutbildung. Arch. der Heilkunde. Bd. X.

2. Derselbe, Neue Beiträge zur Kenntniss der Blutbildung. Archiv d. Heilk. Bd. XV.

3. Derselbe, Archiv für mikroskopische Anatomie. Bd. XII. S. 793.

4. Derselbe, Ueber die myelogene Lenkämie. Berl. klin. Wochenschr. 1878. No. 10.

5. Bizzozero, Rendiconti del Reale Istituto Lombardo. Fasc. f. Volum. 2. Sui corpusculi semoventi del Paolo Mantegazza. 1865.

6. Derselbe, Sulla midollo delle ossa. Napoli 1869.

7. Rindfleisch, Ueber Knochenmark und Blutbildung. Archiv für mikrosk. Anat. Bd. XVII. S. 1.

8. Derselbe, Exper. Studien über Histologie des Blutes. Leipzig 1863.

9. Kölliker, Archiv f. ration. Medicin. Bd. IV. 1846. S. 112.

10. Derselbe, Gewebelebre. 1867.

11. Brücke, Physiologie. Russische Uebersetz. Petersburg 1876.

12. Ranvier, Technische Histologie. Russische Uebersetz. Petersburg 1875.

13. Hayem, Recherches sur l'évolution des hématies dans le sang de l'homme et des vertébrés. Archives de Physiologie normale et pathologique. T. 5 .

14. Derselbe, Gazette médic. de Paris. 1879. No. 15.

15. Peremeschko, Centralbl. f. d. medic. Wiss. 1879. No. 32.

16. Arndt, Dieses Archiv Bd. 78. S. 1.

17. Cohnheim, Dieses Archiv Bd. 68. S. 291.

18. Erb, Dieses Archiv Bd. 34. S. 138.

19. Orth und Litten, Berl. klin. Wochenschr. 1877. No. 51 .

20. Orth, Cursus der norm. Histalogie. Berlin 1878.

21. O sler, Gentralblatt f. d. med. Wiss. 1878. No. 26.

22. Mischer, Medico-chemische Untersuchungen von Hoppe-Seyler. Heft IV.

23. Flemming, Arch. f. mikrosk. Anat. Bd. XVI.

24. Derselbe, ibidem Bd. XVIII.

25. Wis sotzky, ibidem Bd. XIII. S. 479.

26. Foà e Salvioli, Arch. per le scienz. medic. IV. Bekannt nach dem Referat im Centralblatt f. d. medic. Wiss. 1880. No. 7.

27. Semmer, Ueber die Faserstoffbildung im Amphibien- und Vogelblut und die Entstehung der rothen Blutkörperchen bei Säugethieren. Dissert. Dorpat 1874.

28. Zimmermann, Rust's Magazin. Bd. 66. S. 171.

29. Moleschott, Müller's Archiv 1853.

30. Senftleben, Dieses Archiv Bd. 77. S, 421.

31. Stricker, Medicin. Jahrbücher. 1878.

32. B ode, Ueher die Metamorphose der rothen Blatkörperchen. Diss. Dorpat 1866.

33. Golubeff, Arch. f. mikrosk. Anatomie. Bd. V. S. 49.

34. Derselbe, Sitzungsberichte der Wien. Akad. Bd. 57. S. 555.

35. Derselbe, Vorträge der Histologie. 1875. Petersburg. (Russisch.)

36. Weigert, Dieses Archiv Bd. 79. S.87.

37. Kirilow, Archis der Veterin.-Wissensch. 1879. Mai. (Russisch.) 


\section{Erklärung der Abbildungen.}

Tafe] IX.

Fig. 1. Die concentrische Kernbildung in der blassen Zelle.

Fig. 2. Radiäre Kernbildung im Hämatoblasten.

Fig. 3. Der Austrittsprozess des Kernes aus dem Hämatoblasten.

Fig. 4. Die Reihe der Abweichungen von den typischen Formen der Kernbildung bei der Anfertigung des Präparates ohne Reagens.

Fig. 5. a Der vitale Zustand des Hämatoblasten in der Theilungsperiode. b Der Anfang der Kernbildung im sich theilenden Hämatoblasten nach dem concentrischen Modus. $c$, $d$ und e Die Formen, welche nicht selten bei Anfertigung des Präparates ohne Reagens beobachtet werden.

Fig. 6. Unreife rothe Blutkörperchen nach Einwirkung der wässrigen Lösung von Methylviolett.

Fig. 7. Kurzes Schema der Histogenese der Elemente des Knochenmarkes. a Blasse Zellen. b Hämatoblasten. c Rothe Blutkörperchen. d und e Gewöbnliche Markzellen. 


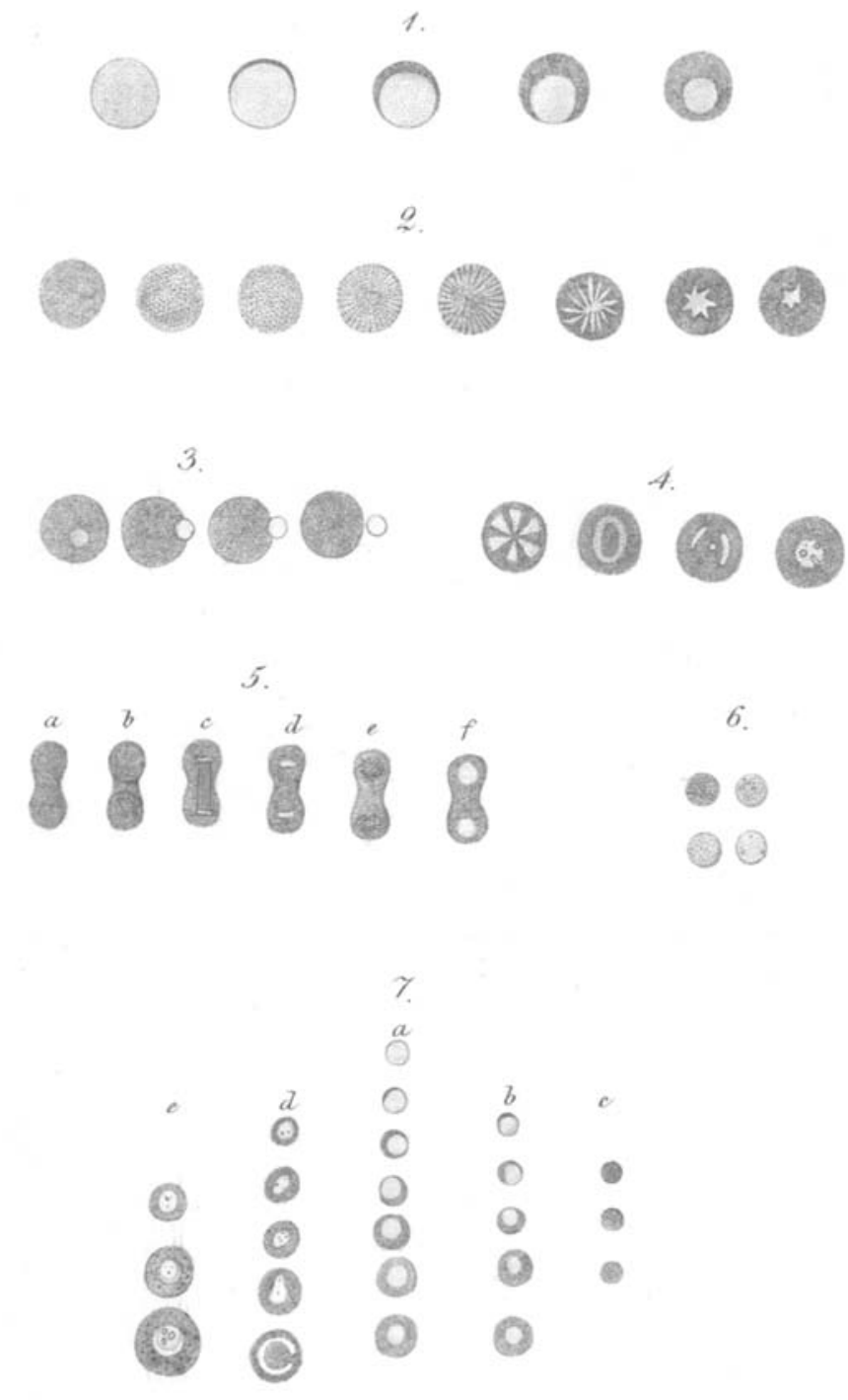

İridaro da. 